\title{
Keep the faith in banking: New evidence for the effects of negative interest rates based on the case of Finnish cooperative banks ${ }^{\text {is }}$
}

\author{
Juha Junttila $^{\text {a, *, Jukka Perttunen }}{ }^{\text {b, Juhani Raatikainen }}{ }^{\text {a }}$ \\ ${ }^{a}$ University of Jyväskylä School of Business and Economics, Finland \\ ${ }^{\mathrm{b}}$ Oulu Business School, Finland
}

\section{A R T I C L E I N F O}

\section{JEL classifications:}

C32

C58

G15

G21

Keywords:

Banks

Profitability

Negative interest rates

Dynamic conditional correlations

\begin{abstract}
A B S T R A C T
This paper analyses the profitability of Finnish cooperative banks during the period of negative nominal interest rates. Contrary to expectations, the continuous decline in money market interest rates between 2009 and 2014, and the following negative rate era, did not have adverse effects on the profitability of banks at the beginning of negative interest rate period. Based on especially using a risk-adjusted measure for bank profitability, these results contrast with previous findings. In our findings, the increasing wholesale funding (WSF) ratio seems to be an important factor. However, after 2017 the banks have not been able to improve especially their risk-adjusted profitability so strongly anymore, because the WSF and the development of other than net interest margin returns have been in negative connection to it. In addition, the unconventional monetary policy actions seem not to improve profitability in the most recent observations of our data. These results raise serious concerns for the future of bank profitability during the prolonged period of negative interest rates.
\end{abstract}

\section{Introduction}

Most European countries and their aggregate economies have witnessed a period of negative short-term money market interest rates for over six years at the time of writing. For example, after the main European Central Bank (ECB) steering rates broke the zero-floor limit in the summer of 2014, initiating the era of negative money market interest rates, the Euro Overnight Index Average (EONIA) rate fell below zero in November 2014 and has been there ever since that. After that, the Euribor interest rates followed the path, first at three months' maturity in April 2015 and then at 12 months' maturity in February 2016. ${ }^{1}$ Especially due to the extremely severe COVID-19 crisis, there is still an alarmingly strong need for expansive (unconventional) monetary policy actions in the near future. Hence, the conclusion of the negative interest rates era has yet to appear probably far on the future horizon.

This extraordinary, textbook contrarian phenomenon in financial markets has been found to be harmful for the profitability of banking sector in most of the earlier studies. This is due to the obviously declining profits based on the sector's main source of returns, the net interest margin (NIM). However, the most recent literature on bank profitability has suggested that the effects of negative reference rates on banks' profitability might actually be dependent on banks' respective business models. ${ }^{2}$ Moreover, since the era of negative interest rates clearly appears to be lasting longer than originally planned by the ECB

\footnotetext{
w We are extremely grateful to Ari Saarinen and Arto Kuhmonen from the OP Group's business control department for providing us with the original, highly confidential bank-level data set, and to senior risk manager Esa Vilhonen for many discussions about the principles of the Group's control activities and permission to publish the results reported in this paper. We are also grateful to Tomi Kortela for providing us the shadow interest rate data. In addition, discussions with and help from Jaakko Sääskilahti and Petteri Juusola from the OP Group were helpful during the early stages of our research, and the comments from Rima Turk-Ariss, Jaakko Pehkonen, and participants at the virtual FMA2020 conference (New York) were very helpful, too. Last but not least, we are extremely grateful to the Editor Brian Lucey, and three anonymous referees, whose comments improved the quality of this research a lot.

* Corresponding author at: University of Jyväskylä School of Business and Economics, PO Box 35, FI-40014 University of Jyväskylä, Finland.

E-mail address: juha-pekka.junttila@jyu.fi (J. Junttila).

${ }^{1}$ See Heider et al. (2019) for a more detailed description of the events in the interbank markets and central bank funding at the European level since the first decrease in the ECB deposit facility rate (DFR) to below zero on June 11, 2014.

${ }^{2}$ See e.g. Roengpitya, Trashev and Tsatsaronis (2014) for the classification of banks based on their business models, particularly with regard to sources of funding. The key factor in the division of banks based on their different business models is each bank's dependence on funding sources, i.e., is the funding deposit- or wholesale-based, and how are the banks diversified geographically and by business line (see also Chen et al., 2018)
} 
policy makers right after the global financial crisis, ${ }^{3}$ banks that were previously largely retail-based (deposit-funded) might have had an incentive to move towards a more wholesale-based funding model, since borrowing from interbank markets with a negative interest rate actually improves the NIM. In practice, this is due to the negative interest payments on new interbank loans obtained from the market, and the previously observed general unwillingness of banks to pay negative interest rates on their customers' deposits. ${ }^{4}$ For the special case of Finnish cooperative (OP, where the abbreviation comes from the Finnish word osuuspankki) banks, it is worth emphasizing here, at the beginning of our analysis, that none of the individual banks alone would have been able to materialize the prominent positive effects of the extremely low costs of wholesale funding. This is because, in terms of their sizes and other conditions, they would have been unable to access the market as individual, independent entities. Hence, the benefits of low funding costs have only been available to them through the central cooperative's access to the European interbank markets. ${ }^{5}$ Another important component related to interbank activities in general is that, in the special case of Finnish OP banks, the balances for liquidity reserves (and their requirements) have always been managed centrally (i.e. by the central cooperative), so the individual member banks have not been required to meet these obligations. This has clearly also had a direct impact on the profitability of the member banks, as all costs related to these activities have been centralized. ${ }^{6}$

\footnotetext{
${ }^{3}$ Based on a thorough analysis of the potential role of negative paper currency interest rate (PCIR), in particular, within the entire banking system in modern, digitalized economies, Agarwal and Kimball (2019) argue that deeply negative interest rates, (i.e. nominal rates below - 1\%), at least for a short time period, might even be an effective monetary policy tool in the future. They propose that central banks should actually adapt to using them more permanently in their fight against recessions, because similar mechanisms in the transmission of monetary policy actions to the real economy might still be valid under the episodes of negative interest rates, as there are during positive rate eras.

${ }^{4}$ In relation to the strong need for unconventional actions to continue, already before the onset of the current Corona crisis, there were numerous discussions about the possibility that banks will also pay negative interest rates on customer deposits. For example, in August 2019, the Danish Jyske Bank launched the world's first negative interest rate mortgage - handing out loans to homeowners with charges of minus $0.5 \%$ a year. Furthermore, the Nordea Bank informed approximately at same time that it will begin offering 20-year fixed-rate deals at $0 \%$ and a 30 -year mortgage at $0.5 \%$, that are extremely low levels for longer term interest rates applied by banks (see,https://www. theguardian.com/money/2019/aug/13/

danish-bank-launches-worlds-first-negative-

interest-rate-mortgage). In addition, Altavilla, Burlon, Giannetti, and Holton (2019) actually have shown, based on their confidential euro area data, that sound banks within the ECB system had actually begun to charge negative interest rates on corporate deposits already quite soon after the DFR became negative in June 2014, and the corporate deposit rate was even lowered below the DFR in some banks.

5 At the end of 2017, the entire Finnish OP Group was only the fiftieth largest of all European banks based on the size of its balance sheet. Hence, although it currently holds a $40 \%$ market share in many of the main customer business activities in the Finnish banking markets, even the whole OP Group does not belong to the major systemically important banks (SIB) at the European level.

6 This is one example of the principle of joint and several liability to which the OP Group adheres (see Appendix A).
}

The main purpose of this study is to analyse the connections between a set of four highly relevant measures of bank profitability before and during the negative money market interest rate era. The key profitability measures are the risk-adjusted measure for the return on economic capital (ROEC) ${ }^{7}$; the standard, most frequently used measures of return on assets (ROA) and return on equity (ROE); and, above all, the main component of bank's profitability, particularly during periods of normal market conditions with positive reference rates, i.e. the NIM. Our study will focus on carefully revealing, first, the effects of changes in nominal money market interest rate (EONIA mid-rate) on each of the individual profitability measures. Second, we also aim to reveal the specific effects of negative market interest rates on this relationship. Third, we are interested in whether the introduction of negative money market interest rates has induced a change in the banks' business models, i.e. from deposit-based funding to more wholesale-based funding, that has been based on negative loan interest rates for the banks. For all these purposes, we will use a unique, strictly confidential bank-level balance sheet and financial statement data from all the banks belonging to the Finnish group of cooperative banks, the OP Group. Within the OP Group, the prominent structural change in the individual banks' business models may have been partly caused by the introduction of negative interest rates. This is because soon after the quotation of the negative money market interest rates began, the central cooperative of the Group began to grant loans to member banks with negative interest rates, particularly at the shorter end of the maturity spectrum. This was mainly based on the principle of joint and several liability (see Appendix A), which particularly stresses the idea of common benefits and liabilities among all banks in the Group. Hence, when the central cooperative is able to obtain funding from the market with a negative interest rate, it passes this funding possibility, with a slightly higher (but still negative, depending on the maturity of the loan) interest rate through to the individual member banks also in need of funding. We are particularly interested in ascertaining whether this has occurred in the OP Group on a larger scale, and what are its effects on average bank profitability of the OP banks of different sizes within the Group.

The original data used in this study are monthly observations from the period 1/2009-12/2018 on each member bank of the OP Group. For example, the top managers and boards of directors in all the individual banks follow these data carefully in the form of monthly reports produced by the headquarters of the OP Group. Following a reasonably large number of mergers during the period under analysis, at the end of our sample (in December 2018), the final number of banks in our data set was 151. In our empirical analyses, we will use the average values for the profitability measures calculated based on classifying the banks into largest (denoted R1; $n=23$ ), medium-sized (R2; $n=39$ ), and smallest (R3; $n=89$ ) banks. $^{8}$

In addition to using various profitability measures, one of our main targets is to analyse the differences between the three bank size categories to determine whether the extraordinary period of negative interest rates has affected them differently. In the empirical analysis, we will focus particularly on the dynamic relationships between the analysed average profitability measures, paying less attention to the actual factors affecting the profitability of individual banks in different operating environments. In other words, we aim particularly to adopt a

\footnotetext{
${ }^{7}$ In some earlier studies on bank profitability, a corresponding term has been the return on risk-adjusted capital (RORAC). The main principle in the calculation of ROEC is the same, i.e. the risk-adjustment of the denominator in the profitability measure. However, in the special case of Finnish cooperative banks, we wish to stress the connection of ROEC in particular to the actual measurement of economic capital, that is, the economic profit in euros that accounts for all return and cost items and the costs in relation to their risk in the form of actual capital requirement.

${ }^{8}$ See section 3 on empirical strategy and data for further details about the classification of the individual OP banks to R1, R2 and R3 banks.
} 
stance on whether the risk-adjusted measure of profitability (ROEC) used by the OP Group behaves very differently compared to the standard, non-risk-adjusted measures (ROE and ROA), and what the role of negative money market interest rates is in terms of the difference between these measures of bank profitability. Furthermore, we also wish to reveal whether the NIM, as the main component affecting all the fundamental profitability measures, behaves differently in terms of its connections to them during the negative interest rates, compared to more 'normal' times.

Our study makes four main new contributions to the extant literature on the effects of negative interest rates on bank profitability. First, we are not aware of any other study that has used such an extensive riskadjusted profitability measure (ROEC) in comparison to more standard profitability measures, such as ROE and ROA. Second, this is the first study to analyse the dynamic connections of NIM to both risk-adjusted and non-risk-adjusted profitability. Third, we use a practically oriented, monthly data set that enables us to use modern time-series techniques due to the reasonable number of observations. Finally, our study focuses particularly on the differences in the results between the banks of various sizes, i.e. small, medium-size, and large banks (in the Finnish scale). Hence, from a policy and practically oriented point of view, our results will also give some completely new background information for the discussions about the role of negative interest rate era on the profitability of banks of different sizes, and for the ongoing discussions on e.g. the need for structural changes (i.e., number of banks) within the Finnish OP Group.

Based on our thorough time-series analysis, we obtained the following results for the relationships between the average values of the different profitability measures in the three bank size categories and the chosen money market interest rate, the EONIA overnight mid-rate. First, we find that, in contrast to most earlier studies on this theme, the introduction of negative money market interest rates in European interbank markets since 2014 did have a positive effect in general on the profitability of Finland's OP banks during the first couple of years. However, this conclusion is considerably dependent on the measure of profitability used in the analysis. The results are strongest with respect to the profitability of the largest cooperative banks and when using the risk-adjusted measure (ROEC) as the measure of profitability. The second key finding from our research is that the increasing wholesale funding ratio during the era of negative interest rates has played an extremely important role.

Additionally, our results reveal that it is methodologically vital to control for the almost-zero volatility of the money market interest rates and NIMs when executing the profitability analysis of banks during the negative interest rate era. Our dynamic time series modelling approach reveals that also the risk-adjusted profitability might have started to suffer from the beginning of 2017, because even the biggest (R1) banks have not been able to improve their profitability anymore. Reason for this might be that the benefits of using more WSF with negative central bank loan rates have been exploited fully, and accordingly, the development of returns also e.g. from other income components has been very modest or even in negative connection to the profitability after that. Hence, our results raise extremely serious concerns for the near-term profitability of banks due to the obvious continuation of negative interest rates in Europe at least during the real economic survival period from the COVID-19 crisis. Our results serve as a primer for more detailed analysis of all the components affecting bank profitability during the negative interest rate era that appears likely to persist long into the future now. Furthermore, at least in the case of Finnish OP Group, the profitability dependence on especially the negative market interest rates of smaller, R2- and R3-size banks is somewhat different compared to the R1-size profitability. Hence, it also seems that if we assume that the negative interest rate period continues, merger discussions and plans involving only small sets of banks belonging to the intermediate (R2) and small (R3) banks are not very relevant for the purposes of improving the overall profitability of the merger banks. Another very much policy relevant finding from our results is that even though it seems to be the case that the unconventional monetary policy actions (QE) have had a lowering effect on the bank profitability risk premium, defined here as the difference between the risk-adjusted (ROEC) and non-risk-adjusted (ROE) profitability, the last two years of data also witness a decreasing effect on overall profitability of banks as the market interest rates and also the shadow interest rate have remained in the negative era, and even still lowered from time to time. According to our results, already from a risk balancing point of view, the optimal new, mergerbased conglomerates within the group should always also include (at least) one bank from the group of biggest (R1) banks. This result also introduces a strong need to conduct all these profitability analyses using a much larger, international panel dataset on banks of different sizes, and importantly, also with different ownership structures.

Our study is structured as follows. In the next section, we describe the most relevant extracts from the previous literature on our theme. Section 3 describes the data and empirical strategy in details. Section 4 reports the empirical results. Finally, Section 5 discusses the implications of our results for the current mainstream literature on bank profitability, presents conclusions, and offers suggestions for future research.

\section{Related literature}

An early study emphasizing the role of banks' funding strategies (before the 2008 financial crisis and the current era of negative money market interest rates) is the one by Demirgüç-Kunt and Huizinga (2010). They examined the implications of bank activity and short-term funding strategies for bank risk and returns using an international sample of 1334 banks in 101 countries before the subprime mortgage crisis. One of their main findings was that the expansion of bank activities into noninterest income-generating items, such as trading, increased the rate of ROA and that it could offer some risk diversification benefits at very low levels. However, an interesting finding that is particularly relevant to our study is that, prior to the global financial crisis, the non-deposit, wholesale-based funding lowered the rate of ROA, while it could have offered some risk reduction at commonly observed low levels of nondeposit funding. Demirgüç-Kunt and Huizinga (2010) also pointed out that a sizeable proportion of banks attract most of their short-term funding in the form of non-deposits at a cost of enhanced bank fragility. Overall, their results clearly suggested that before the period of negative money market interest rates, banking strategies that relied prominently on generating non-interest income or attracting nondeposit funding were deemed to be very risky, consistent with the demise of the US investment banking sector.

More recently, Köhler (2015) analysed the impact of banks' business models on bank stability in $15 \mathrm{EU}$ countries between 2002 and 2011 . He proxied the banks' business models by the share of non-interest income in total operating income and the share of non-deposit funding in total liabilities. In contrast to most earlier studies, he also included numerous unlisted banks in the sample, which even now represent majority of banks in the EU. He found that banks would be significantly more stable and profitable if they were willing to increase their share of non-interest income, so income diversification plays a major role in bank profitability and riskiness. He also found that such benefits are particularly large for savings and cooperative banks, whereas investment banks become significantly more precarious due to income diversification. Furthermore, according to Köhler's results, diversification into non-deposit funding will also have a different impact. While retail-oriented banks will be significantly less stable if they increase their share of non-deposit funding, investment banks will be significantly more stable. Hence, he calls for further analyses on data sets that would distinguish clearly between banks following different kinds of business models.

From a slightly different perspective, Berger and Bouwman (2013), for example, focused particularly on the role of bank capital in enhancing the bank's performance. Their study analysed how capital affects a bank's performance (survival and market share) and how this 
effect varies across banking crises, market crises, and periods of normality that have occurred in the US over the last quarter-century. They found that increasing the amount of bank capital particularly helps small banks to increase their probability of survival and market share in all times. Furthermore, capital also seems to have enhanced the performance of medium and large banks, primarily during banking crises.

With greater emphasis on the role of the general situation in the interest-yielding asset markets, the effects of the so-called slope of the yield curve on bank profitability were scrutinized in Alessandri and Nelson (2015). They presented a model of a monopolistically competitive bank subject to repricing frictions and tested the model's predictions on UK banks, using a unique panel data set. Their analyses yield evidence that large banks retain a residual exposure to interest rates, even after accounting for hedging activity operating through the trading book. Furthermore, in the long run, both the level and slope of the yield curve contribute positively to profitability, which follows the standard way of thinking about the effects of changes in the market reference rates on bank profitability through the NIM. In the short term, however, they found that increases in market rates compress interest margins, consistent with the presence of non-negligible loan pricing frictions.

Although the period of negative interest rates has prevailed for clearly over six years now at the European level, literature analysing its actual effects on bank profitability and/or riskiness remains surprisingly limited. Focusing particularly on Nordic countries, Turk-Ariss (2016) used bank-level data from large Danish and Swedish banks to demonstrate that the bank margins of loans to customers have remained broadly stable during the era of negative interest rates. Hence, reductions in wholesale funding costs and higher fee income have offset the lower interest income, and bank profitability has not suffered much due to negative reference rates in Sweden and Denmark. However, TurkAriss also warns that this situation may affect the banking sector's overall health, and so negative interest rates and their effects on the banking sector should be closely monitored in the future.

Bikker and Vervliet (2017) focused specifically on the US banking sector data from 2001 to 2015 and used the standard profitability measures, i.e. the NIM, ROA, ROE, and profit as reported in the bank's balance sheet (as a ratio of total assets). For risk measurement, they used the total capital ratio (TCR, the ratio of total risk-based capital over riskweighted assets), and the loan loss provisions to total loans ratio. These risk measures were used as explanatory variables in one setting and as dependent variables in another. The vectors of explanatory variables in the panel regressions were a set of bank-specific variables and two macro variables (real GDP growth and CPI inflation), and as the shortterm interest rate, they used the three-month money market interest rate. Their main finding was that the low interest environment indeed impairs banks' performance and compresses NIMs. However, US banks have been able to maintain their overall profit levels due to lower provisions (for loan losses etc.), but this induces greater risk for financial stability. Furthermore, US banks do not appear to have compensated their lower interest income by expanding operations to include trading activities with higher risk exposure.

Recently, Chaudron (2018) has also highlighted the special role of interest rate risk in bank profitability. He analysed the size and development of interest rate risk in the banking book positions of Dutch banks between 2008 and 2015. According to his results, due to hedging, interest rate risk has been minor, and the income from maturity transformation has actually formed a small share of the NIM and the ROA. However, in his data set, interest rate risk positions vary significantly between banks and over time, and he suggests that banks lower their interest rate risk significantly when the yield curve flattens. Furthermore, he suggests that interest rate risk is negatively related to onbalance sheet leverage and has a U-shaped relation with solvability for banks that do not use derivatives. Additionally, banks that had received government assistance during the financial crisis had higher interest rate risk than banks that had not received assistance.
In the most recent studies focusing specifically on the period just before or during negative interest rates, Claessens, Coleman, Donnelly, and M. (2018) used data from 3385 banks and 47 countries over the period 2005-2013 and found that a one percentage point drop in the reference rates during this time resulted in, on average, NIM of 8 basis points lower for banks. ${ }^{9}$ However, the effect has been 20 basis points at low interest rate levels, i.e., non-linear. Hence, extremely low interest rates do affect bank profitability negatively, but with significant variation. According to their results, for each additional year of 'low-for-long' interest rates, margins, and profitability fall by another 9 and 6 basis points, respectively. Detragiache, Tressel, and Turk-Ariss (2018) analysed the profitability of banks at the EU level and found that banks whose profits have not decreased significantly during the zero-lower bound (ZLB) and negative interest rates period have experienced less deterioration in loan quality and considerable improvement in cost efficiency. These banks also downsized their assets more aggressively in response to the crisis and reduced their reliance on wholesale funding after the crisis. They also found that the NIM remained stable throughout the whole sample period they analysed, and the results showed no evidence that the reliance on fees and commissions would have improved profitability after the crisis.

Discussions of changes in the bank business models enhanced by the negative interest rate era were also the focus of Chen, Katagiri, and Surti (2018), who argue that if the scenario of very low and negative interest rates continues very long, it also implies low values for the longer-term, natural real interest rate. This may induce more consolidation waves in the banking industry in the long run. Furthermore, based on their theoretical model, and especially empirical data from Japan (and other industrial countries), they also argue that demographic factors, low productivity growth, and advances in financial technology will likely cause significant shifts in banks' business lines under low and/or negative interest rates. Furthermore, in a scenario of low rates and advances in financial technologies, banks may lose their market share in the debt financing of larger companies, when the non-banking sector is better able to price the corporate credit risk, and large firms seek more for bond market funding with low interest rates.

Also focusing particularly on NIM behaviour, Angori, Aristei, and Gallo (2019) analysed its determinants during the period 2008-2014 in the euro area. The starting point for their analysis was the premise that this standard measure of bank profitability should still be the main gauge of financial institutions' health and stability. Besides considering the main bank-level drivers affecting the NIM, such as market power, capitalization, interest risk, and the level of efficiency, they also accounted for the effects of regulatory and institutional settings. Their results reveal a persistence in the vulnerability of the banks' sustainable profitability, although this negative trend has been partially mitigated by the ECB's recent monetary policies. The increase in non-traditional activities seems to have contributed significantly to the slowdown in bank margins from traditional activity. Furthermore, the differences in the regulatory environment have effects on NIM, which has remained lower in countries with higher capital requirements and greater supervisory power.

Bottero et al. (2019) have studied the negative interest rate policy (NIRP) exploiting the ECB's introduction of NIRP and administrative data from Italy, whose real economy and banking sector were severely hit by the eurozone crisis. According to their results, the NIRP has expansionary effects on credit supply and, hence, the real economy, through a portfolio-rebalancing channel, and it affects banks with higher ex-ante net short-term interbank positions or, more broadly, more liquid balance sheets, but not those with higher retail deposits. NIRP-affected banks rebalance their portfolios from liquid assets to

\footnotetext{
${ }^{9}$ Other very recent papers focusing especially on the determinants of NIM profitability and comparison between different bank sizes are e.g. Kusi et al. (2020) and Asongu and Odhiambo (2019).
} 
credit-especially to riskier and smaller firms-and cut loan rates, inducing sizeable real effects. Hence, by shifting the entire yield curve downwards, NIRP differs from rate cuts just above the ZLB.

In one of the most recent studies Lopez, Rose, and Spiegel (2020) performed an explicit analysis on the effects of negative nominal interest rates on bank profitability using annual data from 5200 banks in 27 countries from the period 2010-2017. They used proxies for the country-level local conditions as instruments for the negative interest rates and other explanatory variables and split the data set based on the bank size (amount of assets) and reliance on deposit, i.e., retail funding. One of their main findings is that the effects of negative interest rates are clearly heterogeneous. Banks from regimes with floating exchange rates, small banks, and banks with low deposit ratios drive most of the results. It appears that low-deposit banks have enjoyed particularly striking gains in non-interest income. Additionally, banks responded to negative interest rates with increased lending activity and by raising the share of deposit funding. In sum, the effects of negative interest rates on bank profitability seem to have been relatively benign in their data set. In another very recent paper, Heider, Saidi, and Schepens (2019) used a differences-in-differences method and compared the lending behaviour of eurozone banks with different deposit ratios around the ECB's introduction of negative policy rates in June 2014. Hence, they also focus particularly on the role of retail- vs wholesale-based funding of banks' lending activities. They find that the introduction of negative interest rates in funding leads to increased risk taking among banks as a whole and less lending on the part of banks that are more dependent on deposit funding. Hence, they suggest that negative interest rates are less accommodative and could pose a risk to financial stability if lending activities are concentrated in high-deposit banks.

Finally, among the few theoretical papers that have investigated the explicit role of negative interest rates on bank profitability are studies by Eggertsson, Juelsrud, Summers, and Wold (2019) and Xu, Hu, and Das (2019). In the former paper, an essential finding from their empirical analyses is that, as deposit rates stopped responding to policy rates at the ZLB, bank lending rates in some cases actually began to increase rather than decrease in response to the policy rate cuts. Hence, the increase in lending margins has improved banks' profitability. In the study by Xu et al. (2019), one of the main findings, which also derives from the theoretical argumentations based on a profit maximization model of a bank, is that the movement from retail-based funding to wholesalebased funding might actually pose a serious threat to the systemic stability of the entire banking sector. Their main finding is that a bank's profitability is negatively correlated with its contribution to systemic risk and its idiosyncratic risk. Additionally, over-reliance on non-interest income, wholesale funding, and leverage is associated with higher risks. Moreover, reduced competition between banks also induces greater contribution to systemic risk. Hence, their main policy suggestion is that policy makers should aim for an improved understanding of bank profitability, particularly in conditions of negative interest rates and banks' increased share of wholesale funding.

As can be seen from our brief literature review, the effects of negative money market interest rates in the banking sector are currently under considerable scrutiny, but a definitive finding or conclusion with respect to whether the effects on bank profitability, risk-adjusted or not, are positive or negative, has yet to be reached. Some of the most recent (also theoretical) studies seem to indicate that, for some banks, negative interest rates might even improve their profitability. However, a key factor influencing the outcome is the bank business model, i.e., whether the bank in question is more dependent on retail (deposit) or wholesale funding. Next, based on our unique, highly confidential data set from all banks belonging to the Finnish OP Group, we will shed new empirical light on this issue.

\section{Data and empirical strategy}

We will apply several modern time-series econometric techniques in our analyses of the key bank profitability measures. First, we will carefully examine the time series under analysis using descriptive statistics and informative graphs. Thus, we will form an idea of the statistically most appropriate forms (i.e., levels or differences) of the variables for further analyses. Second, we will utilize multivariate time-series analytical techniques to reveal the dynamic connections between the analysed bank profitability measures and the money market interest rate. Finally, we will also test for the presence of conditional heteroscedasticity in the estimated multivariate models, which will also provide indications as to the need for more advanced, GARCH-type timeseries modelling approaches, that will be utilized to draw the very final conclusions of our analyses. In interpreting all parts of our results, we will focus particularly on the negative money market interest rate regime with respect to its effects on the various bank profitability measures.

\subsection{Data description}

Our empirical analysis uses monthly observations from all banks belonging to Finland's OP Financial Group for the period 1/2009-12/ 2018. The original, strictly confidential data were collected from the income statements, balance sheets, and financial statements of all banks included. Many of the variables in the original data set are being regularly (in approximately monthly meetings) followed by the boards of directors of the individual OP banks. However, instead of focusing on individual bank-specific data, ${ }^{10}$ we will here concentrate on average values of the main interesting profitability measures, calculated based on the size reference categories R1, R2, and R3. ${ }^{11}$ The classification of the individual OP banks to R1, R2 and R3 banks made by the central cooperative refers to their reference classes in terms of the volume of customer business activities. The group of biggest (R1) banks includes all the 19 regional banks plus 4 other largest banks comparable in size to the regional banks, decided by the Supervisory Board for the entire OP Group. By definition, the next 40 banks in terms of their size belong to the reference group R2. Finally, rest of the banks form the biggest group of banks in terms of the number of individual banks, but they contribute only to a small part of the whole OP Group customer business activities volume.

At the end of our data sample in December 2018, the number of banks was 151 in our filtered data set (156 according to the Group-level statistics referred to in Appendix A). Because some current OP Group member banks had joined the Group from the local cooperative banks'

\footnotetext{
10 Due to limitations of space, we will analyse the original bank-level panel data set using panel-econometric methods in a separate study.

11 Note that the monthly reporting of the data based on these three size groups is based on the ready-made classification of the banks to these size groups by the central co-operative of the OP Group. Hence, we use this readily given classification through-out the whole sample, and hence, for example the effects of mergers and acquisitions of individual banks have already been accounted for in the actual data reported in the original database. However, because we spotted some outliers and accounting irregularities in the data, a detailed description of some additional stages in the cleaning and construction of the final data set utilized in this study's empirical analyses is given in Appendix C. We are extremely grateful to Ari Saarinen and Arto Kuhmonen from the OP Group Business Control department for providing the original confidential data set on all the OP Group banks, and for the preliminary cleaning of the data on accounting and financial statement figures.
} 
(so-called PoP) group during the latter years of our sample period (e.g. in the third quarter of 2016), owing to their lack of historical observations, particularly from the period before the negative interest rates, they were not included into our data set. However, analogously to the merger-type structural changes that occurred throughout the entire sample period, also in the most recent data, some banks in the OP Group had dropped from the R2 group to R3, while others had moved from R3 to R2. ${ }^{12}$ Hence, in our empirical analyses based on the average values of the R1, $\mathrm{R} 2$, and R3 banks, the number of banks belonging to size category R1 is 23. The R2 category includes 39 banks, and finally, all remaining 89 banks belong to the R3 category, bringing the total number of banks in our data set to 151 at the end of 2018 .

\subsubsection{The development of market interest rate and bank profitability measures}

From a set of various possible reference rates in banking activities (see for example Heider et al., 2019), we will use the EONIA overnight mid-rate as representative of the short-term money market interest rates. It began to obtain negative values since November 2014, following the negative path of the main ECB reference rates in the summer, and was
Although we will start our analysis by also examining the behaviour of ROE values in our data set, we will see that it is strongly correlated with at least two other profitability measures, i.e. the ROA and Net Interest Margin (NIM) values in all cooperative banks, irrespective of their size. This correlation should be borne in mind in the more thorough analyses. ${ }^{14}$

Our third profitability measure is the NIM, defined as

$N I M=\left(\frac{\text { Interest income }- \text { Interest Expenses }}{\text { Assets }}\right) \times 100$.

Evidently, when we specifically analyse the dynamics of the other, broader profitability measures, for example, for this main profitability measure of banks we have

$\Delta N I M \cong \frac{\Delta \text { Interest income }-\Delta \text { Interest expenses }}{\text { Assets }}$,

so changes in both the interest income and expenses have an effect on the overall change in NIM. Furthermore, the ROA and NIM values are also connected to one another by definition, because

$\Delta R O A \cong \triangle N I M+\frac{\Delta \text { Non interest income }}{\text { Assets }}-\frac{\Delta \text { Non interest expenses }}{\text { Assets }}-\frac{\Delta \text { Loan Loss Provisions }}{\text { Assets }}+\frac{\Delta \text { Net other income }}{\text { Assets }}$,

followed by negative values for the main bank reference rates in credit activities, i.e., the 3-month (negative since April 2015) and 12-month (negative since February 2016) Euribor rates. Hence, we treat the EONIA as a 'median indicator' of when the eurozone money market interest rates began to turn (and stay) negative.

The most frequently used standard measure for bank profitability in previous studies is the Return on Assets (ROA), defined as

$R O A=\frac{\text { Net income }(\text { after taxes })}{\text { Assets }} \times 100$.

The amount of assets in ROA calculations is based on the average of the values at the beginning and end of fiscal year, and the tax effects are included as net of appropriations. Alternatively, in some of the previous studies mentioned also in the literature review, profitability has been measured based on the Return on Equity (ROE), that is, ${ }^{13}$

$$
R O E=\frac{\text { Net income }(\text { after taxes })}{\text { Equity }} \times 100
$$

\footnotetext{
${ }^{12}$ See Appendix A for further details on the entire OP Group and its member banks at the end of 2018. Note also that at the beginning of our empirical analyses we detected one individual bank in the R2 group whose accounting and financial statement numbers differed so significantly from all other banks in its reference group that we decided to treat that bank as an outlier, and excluded it from our data set.

${ }^{13}$ The amount of equity includes the minority shares and movable cumulative items at the closing of accounts minus tax effects net of appropriations.
}

\footnotetext{
${ }^{14}$ We would like to point out also that the definition of equity, and hence, its use in analysing the profitability of banks is somewhat ambiguous in the special case of Finnish cooperative banks. This is due to the key role of the member banks in owning the OP cooperative (i.e., central cooperative) through an amalgamation (see Appendix A for more details) and the specific role of customer ownership and profit shares in all the Finnish cooperative banks. By definition, the equity capital of the entire OP Financial Group includes cooperative shares paid by the Group's cooperative bank members, and the bank has an absolute right to refuse to pay interest on them and refund the capital. Cooperative contributions and the ensuing customer ownership entitle the customer to participate in the bank's administration and decision-making. Furthermore, the equity capital of OP Group also includes investments in profit shares made by members of the Group member cooperative bank members, and the bank has an absolute right to refuse to pay interest on them and refund the capital. For example, for 2018-2019, the OP Financial Group sought an interest rate of $3.25 \%$ and will confirm the interest payable annually after the financial year has ended. The return target may change on an annual basis. No customer-owner rights are involved in profit shares, and they do not confer any voting rights. If a member cooperative bank has not refused a refund, the cooperative contribution and the profit share contribution may be refunded within 12 months after the end of the financial year when membership is terminated, or the profit share has been cancelled by its holder. If the refund cannot be made in full in any given year, the balance will be refunded from disposable equity capital based on subsequent financial statements. However, this entitlement to the refund for the balance will terminate after the fifth financial statements. No interest will be paid on the balance. Due to the strong role of especially these cooperative profit shares in the calculation of equity capital (see the OP Financial Group Report by the Executive Board and Financial Statements 2018, and Appendix A), in deeper analyses of the Finnish OP banks' profitability the results on ROE must be scrutinized while bearing these special features in mind.
} 
Hence, it is obvious that other income components besides changes in the NIM might play a significant role in the determination of bank profitability when measured, for example, based simply on the changes in ROA. In calculating the changes in ROA, net other income items usually include non-customer loan impairment charges, net recurring income not related to the core business, extraordinary net income, tax expenses, and profit/loss from discontinued operations (see also Detragiache et al., 2018). ${ }^{15}$

One of the most significant innovations of our study is the use of Return on Economic Capital (ROEC) in analysing the profitability of Finnish cooperative banks. ${ }^{16}$ The main idea in the calculation of ROEC is that it gives a bank-specific measure for the riskiness of bank performance, based on assigning risk values (weights) to the main components of the bank's balance sheet. The fundamental purpose of the requirement for economic capital (EC, the denominator in the calculation of ROEC) is that it is designed to cover for all the risks, particularly in the customer business activities of the OP banks.

According to the information available from the OP Financial Group Intranet, ${ }^{17}$ the EC requirement is the OP Group's own proxy for the amount of capital required to cover all the risks associated with losses from business activities during a single year at the level of $99.97 \%$ probability. This means that if an individual bank has its own funds of the precise amount corresponding to the total EC requirement, the bank runs out of funds once in 3333 years on average. Hence, the EC requirement gives the bank a hedge against extremely rare and unexpectedly large losses. The reason for using the $99.97 \%$ probability level is that it corresponds to the entire OP Group's external credit rating target (level AA). This definition also enables a more direct comparison to the main competitors (e.g. Nordea and Danske Bank) that are using conceptually similar measures for the EC requirement. By definition, in the OP Group, the EC requirement covers the risk categories for credit

\footnotetext{
15 Note that particularly with respect to the NIM calculations, and for all other profitability components, at least two important additional characteristics emerge from our data. First, the loan interest rate floors have been an important factor in the balance sheet management for retail banks because, due to those, the deposit interest rates have also remained approximately at the zero level or just above it. In addition, balance sheet growth plays a role here. In the OP group, based on our data, the NIM has remained approximately constant over the last six years, but the size of the balance sheet has increased by almost one third. During the ten years of our sample, the balance sheet has doubled and the NIM has increased by a third. In the set of profitability measures, ROE and riskadjusted profitability do not capture all these effects, but the ROA, as the measure for capital profitability should also account for these developments.

16 Note that the actual calculation process of ROEC is a highly classified procedure, available in detail only for the bank managers and e.g. the chairpersons of the boards of directors of individual banks in the OP group through the Group's intranet. However, due to the novelty of its application in this paper, the main ideas in the calculation of the ROEC values are described in Appendix B, based on the information obtained from the Group intranet, at the accuracy level accepted by the OP Group business control personnel.

17 Permission to publish this short, very general description of the principles of both the EC requirement and ROEC (in Appendix B) calculations has been obtained from the Group control personnel on 11th December 2019 (e-mail from Esa Vilhonen).
}

risk, for example, is not included. ${ }^{18}$ Indicators based on EC requirement are used within the Group to measure individual banks' general performance. Furthermore, they are used to measure bank-specific limits and Group-level supervision limits in many more detailed performance measures, in rewarding the personnel, pricing the loans and insurance products, and in capital budgeting for the purpose of defining the amounts of capital buffers.

Fig. 1 shows that, after the introduction of negative money market interest rates, the role of equity risk in banking in the EC requirement would seem to have strongly diminished to below half of the situation immediately following the $2008-2009$ crisis. ${ }^{19}$ At the same time, the EC requirement coming from the credit risk appears to have increased by around 13 percentage points. Furthermore, an interesting point that may already be clearly observed from this figure is that both these changes seem to have emerged even more prominently after the introduction of negative money market interest rates around 2014-2015. In addition, the EC requirement emanating from the interest rate risk also clearly seems to have increased permanently after the introduction of negative money market interest rates. Hence, everything that is related to the main, traditional functions of banks (i.e., acquiring deposits and giving loans to customers), seems to have been treated as riskier during the latest 4-5 years, because the EC requirements based on both the credit risk and interest rate risks have clearly increased.

Further details on the actual numerical values and procedures for the calculation of individual components in the EC requirement are available only with the permission from the OP Group Control personnel. For the purposes of our study, we will describe in greater detail only the procedure for calculating the EC requirement for the interest rate risk, because it actually includes currently the scenario of extremely low negative money market interest rates (of the level of even $-2 \%$ in annual terms). Furthermore, as observed from Fig. 1, its role has more than doubled in the EC requirement since the introduction of negative money market reference rates.

The EC requirement for the OP banks' interest rate risk is based on the use of a so-called interest income risk method, which gives a value for the most negative effect on the bank's NIM during the next 12 months (assumed holding period) from a change of four percentage units (positive or negative) in the level of interest rate. The model accounts for the changes in legislation and other conditions in the agreements that allow banks to charge interest from the credit customer corresponding at least to the amount of the customer-specific margin. The calculation of interest income risk also takes into account the effects of negative

\footnotetext{
18 During the sample period, the individual OP banks gave no foreign currency denominated loans to their customers at all. All the currency risks have been centred to the Group level, because the member bank-level currency risks emanating from e.g. the foreign currency-denominated customer deposits have been transferred to the Central cooperative level with counter deposits. The Central cooperative also provides many other types of currency market-related products to all customers, but all the currency market risks are centrally managed and hedged. Hence, the individual member banks do not bear currency risks in their activities at all, other than through the principle of joint and several liability at the group level, again.

${ }^{19}$ Based on discussions with the Group control personnel, the OP banks' equity investments have been reduced to avoid the additional need to acquire market-based funding for these purposes. Hence, the reduction in the equity risk is, for the most part, based on active Group-level guidance.
} 


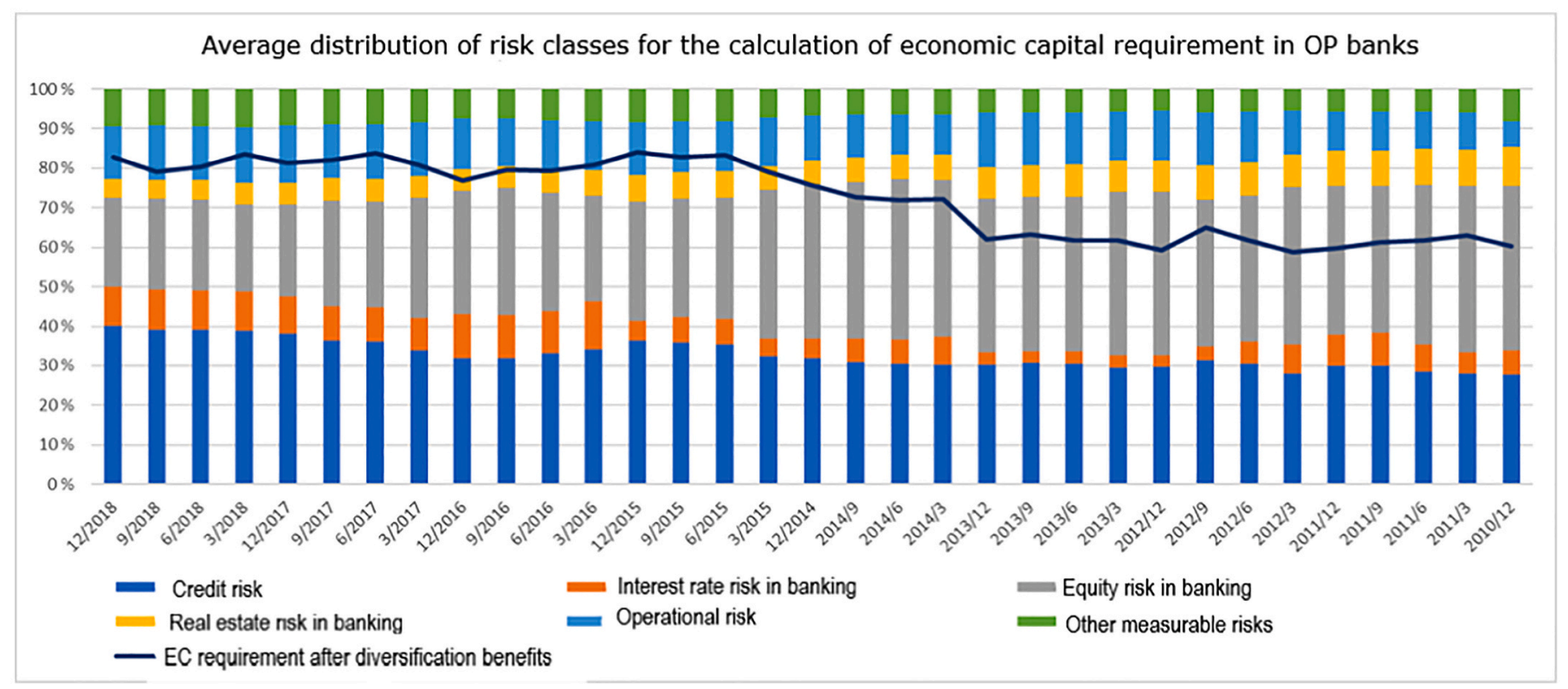

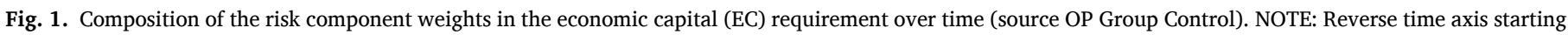
from the most recent observations.

interest rates using the floor of $-2 \% .{ }^{20}$ In addition, debt assets valued at market values are allocated the most negative discounted present value interest rate risk reflected to the bank's own assets for a 4-percentageunit interest rate change during the entire maturity. In this calculation, the floor of $-2 \%$ is also applied. The $4 \%$ change in the calculation is intended to cover both changes in interest rate and credit risk margins.

If an individual bank deposits a special OP-deposit (to the central cooperative), the EC requirement on interest rate risk is based on summing up the interest income risk and a requirement of $2.9 \%$ that is based on a specialist evaluation. The OP-deposit is based on seniority terms, but normally it cannot be withdrawn before maturity. In a specific bank stress situation, an early withdrawal induces costs to the issuer of the performances may also give a somewhat different perspective on the profitability effects of the negative interest rate era. Furthermore, as we have already observed from Fig. 1, the role of different risk classes also seems to have changed after the introduction of negative money market reference rates. However, here it is worth pointing out that many changes in the weights of the risk classes are likely to have been administered by the central cooperative, but the actual decisional data pertaining to these changes are beyond our reach due to their confidentiality. Nevertheless, it is clear, that these decisions probably also reflect the general developments in the interest-yielding asset markets.

In our empirical analyses, the ROEC values are calculated as follows:

$R O E C=\frac{(\text { Operating income }+ \text { customer bonuses }) \times(1-\text { tax rate })}{\text { Economic Capital Requirement on Customer Business Activities (cum. })} \times 100 \%$.

deposit agreement. Taken together, the interest income risk and the present value risk of investments are combined in absolute terms. The $\mathrm{EC}$ requirement of $\mathrm{OP}$ banks is the sum of $\mathrm{EC}$ requirement on interest risk and a separate OP-deposit EC requirement. However, the EC requirement for the interest rate risk of an individual OP is always at least $0.25 \%$ of the total value of the balance sheet, due to the model risk and one-year holding period. This is to ensure that the risk associated with the main income component (NIM) is reflected in all the OP banks. It should also be noted that the interest income risk is not calculated at all for the central cooperative capital and the cooperative capital, additional cooperative capital, or the profit share units of the individual OP banks.

Evidently, both the ROEC and EC calculation procedures have been carefully designed to yield a fundamental picture of the risks involved in all the business activities of the individual cooperative banks. Due to the detailed decompositions of both, the analysis and comparison of ROECbased performance against the most standard ROA- or ROE-based

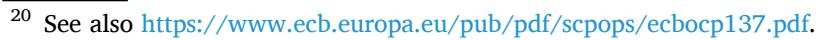

Finally, details regarding how we obtain the monthly (average) observations for each bank size class from the original lower frequency data (used for the calculation of some composites of the main interesting variables) for the three profitability measures utilized in the regression analyses are provided in Appendix C. Figs. 2a-2c show the development of the analysed profitability measures compared to the values of the EONIA overnight mid-rate during our sample period.

From Figs. 2a-2c we see that the standard textbook hypothesis stating that decreasing general market interest rates have a negative effect on the NIM seems to clearly hold in our data, and for all bank size groups. More specifically, when the EONIA turned negative in November 2014, the average NIM profitability in all the OP bank size categories began to decrease, and it has continued to do so up to the most recent observations. However, an interesting new eye-ball finding is that when we measure the profitability by a wider measure, i.e., ROA, the negative effect of below-zero interest rates might not be so clear at all in the data on Finnish cooperative banks. Only after the beginning of 2017 can we clearly say that ROA-based profitability has consistently decreased across all bank size groups in average terms. Furthermore, as 

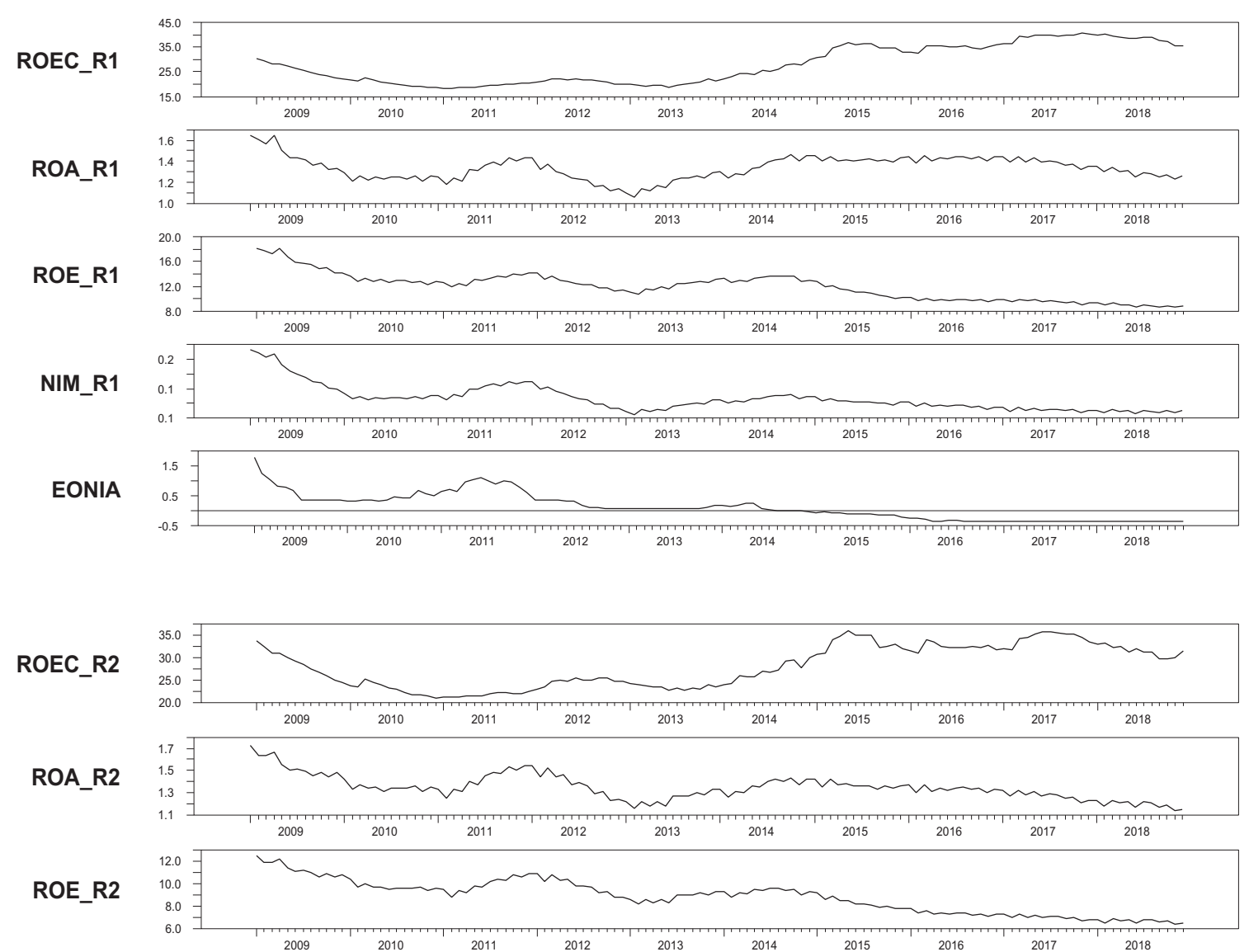

NIM_R2

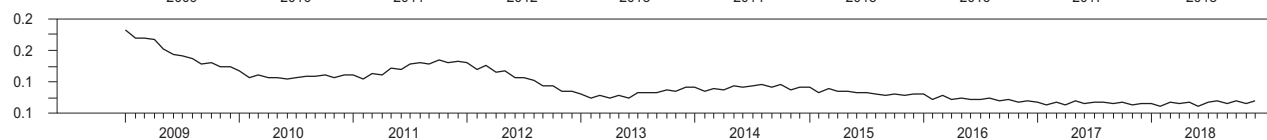

EONIA
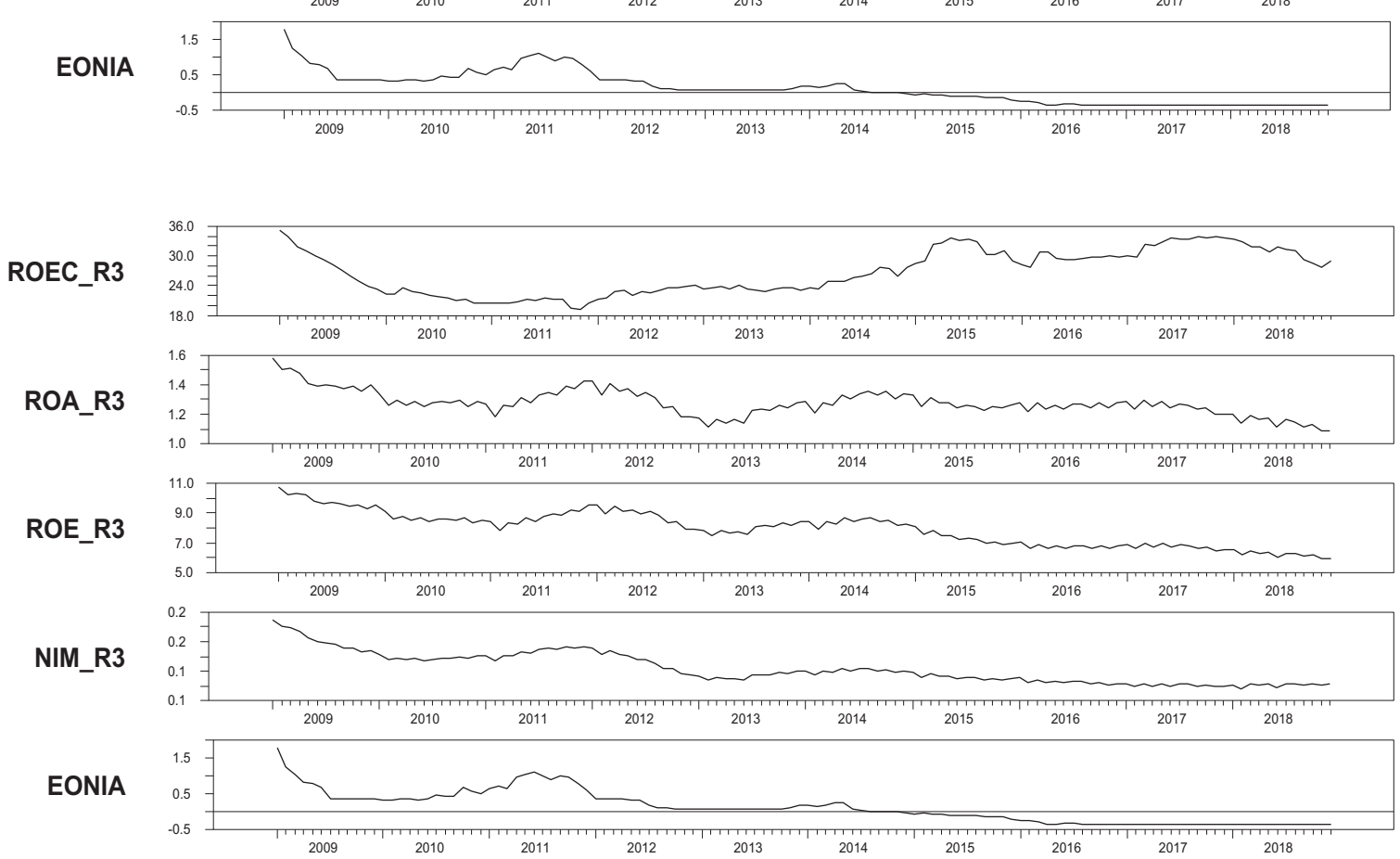

Fig. 2. a. Alternative average profitability measures for R1 banks compared to EONIA mid-rate. b. Alternative average profitability measures for R2 banks compared to EONIA mid-rate. c. Alternative average profitability measures for R3 banks compared to EONIA mid-rate. a*. Differenced values of profitability measures for R1 banks and EONIA $b^{*}$. Differenced values of profitability measures for R2 banks and EONIA. $c^{*}$. Differenced values of profitability measures for R3 banks and EONIA 


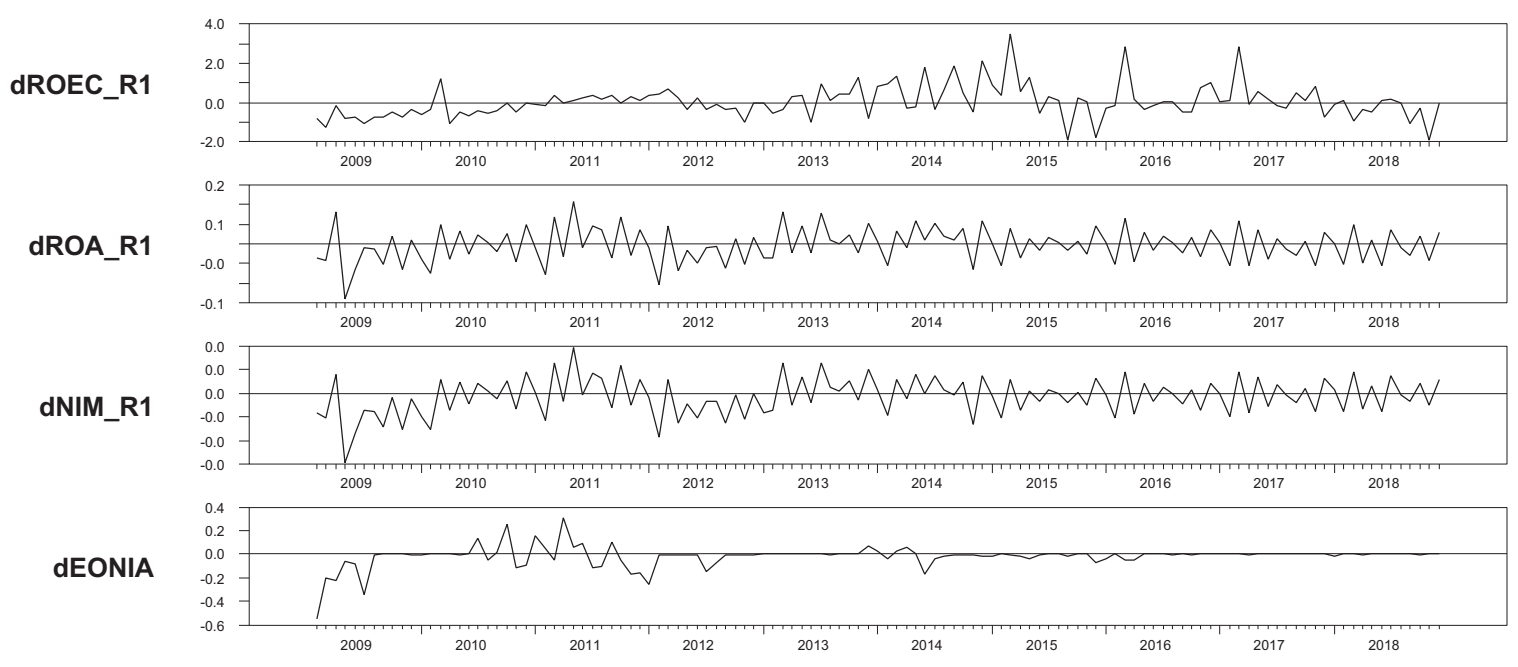

dROEC_R2

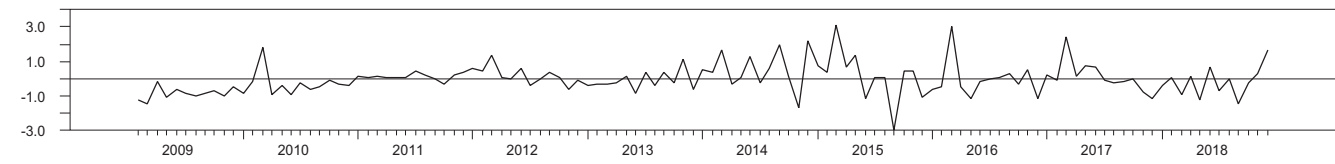

dROA_R2

0.1
-0.0
-0.1
-0.1

dNIM_R2

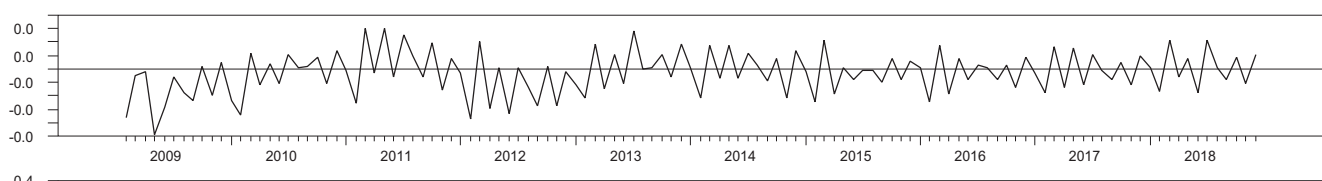

dEONIA

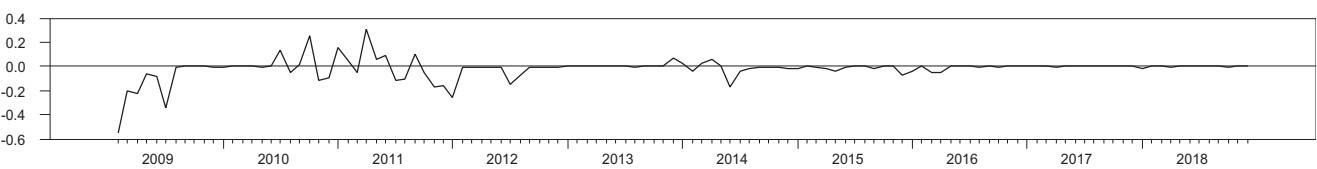

dROEC_R3

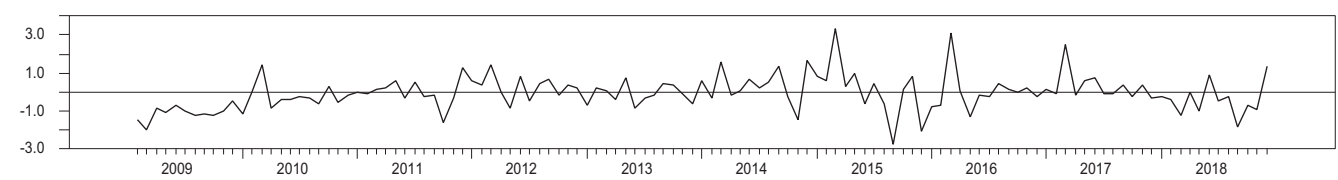

dROA_R3

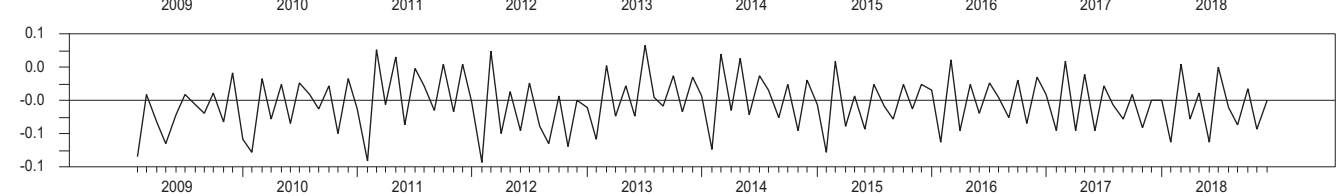

dNIM_R3

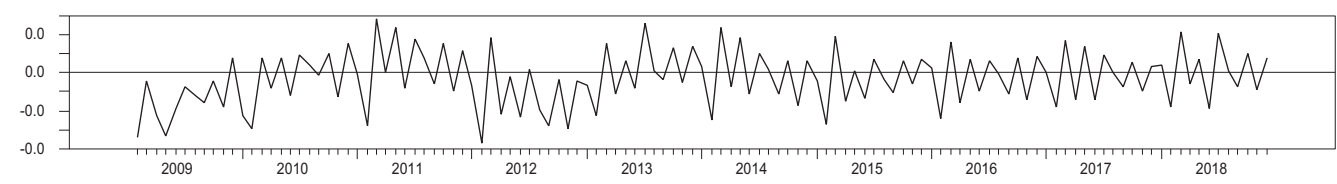

dEONIA

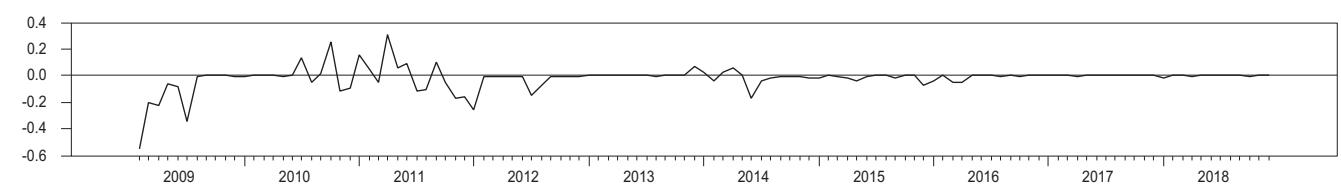

Fig. 2. (continued). 
Table 1

Descriptive statistics, unit root test results, and correlations for the bank profitability measures and the EONIA mid-rate, all measured in \%.

\begin{tabular}{|c|c|c|c|c|c|c|c|c|c|c|c|c|c|}
\hline $\begin{array}{l}\text { Variable / } \\
\text { Descr. stat. }\end{array}$ & ROEC_R1 & $R O E_{-} R 1$ & $R O A \_R 1$ & NIM_R1 & ROEC_R2 & $R O E_{-} R 2$ & $R O A \_R 2$ & $N I M_{-} R 2$ & ROEC_R3 & $R O E \_R 3$ & $R O A \_R 3$ & $N I M_{-} R 3$ & EONIA \\
\hline Mean & 27.95 & 11.94 & 1.34 & 0.11 & 28.20 & 8.84 & 1.36 & 0.12 & 26.77 & 7.94 & 1.28 & 0.12 & 0.13 \\
\hline Std Dev & 7.76 & 2.16 & 0.11 & 0.02 & 5.01 & 1.47 & 0.11 & 0.02 & 4.51 & 1.14 & 0.09 & 0.02 & 0.45 \\
\hline Min & 18.32 & 8.62 & 1.07 & 0.09 & 20.84 & 6.49 & 1.16 & 0.09 & 19.24 & 5.95 & 1.09 & 0.10 & -0.37 \\
\hline $\operatorname{Max}$ & 40.86 & 18.10 & 1.65 & 0.17 & 36.71 & 12.55 & 1.72 & 0.19 & 35.32 & 10.78 & 1.58 & 0.19 & 1.81 \\
\hline $\begin{array}{l}\text { \# of banks in } \\
\text { the size } \\
\text { group }\end{array}$ & 23 & & & & 39 & & & & 89 & & & & \\
\hline \multicolumn{14}{|l|}{$\begin{array}{l}\text { Unit root } \\
\text { tests }\end{array}$} \\
\hline$A D F$ & -0.96 & $-2.92^{* *}$ & $-3.52^{* * *}$ & $-4.46^{* * * *}$ & -1.12 & -1.94 & $-3.04^{* *}$ & $-2.89 * *$ & -1.88 & -1.37 & -2.30 & -2.24 & $-4.35^{* * *}$ \\
\hline KPSS & $1.94^{* * *}$ & $1.94 * * *$ & 0.27 & $1.47 * * *$ & $1.64 * * *$ & $2.18^{* * *}$ & $0.98^{* * *}$ & $2.02^{* * *}$ & $1.40^{* * *}$ & $2.18^{* * *}$ & $1.08^{* * *}$ & $2.14^{* *}$ & $2.11^{* *}$ \\
\hline$Z-A$ & $-5.07^{* *}$ & $-5.27^{* * *}$ & $-5.34 * * *$ & $-6.03^{* * *}$ & $-4.66^{*}$ & $-4.68^{*}$ & $-4.31 *$ & $-5.39^{* * *}$ & $-5.21 * *$ & -4.02 & -3.71 & $-4.76^{*}$ & -3.23 \\
\hline \multicolumn{14}{|l|}{ Break point } \\
\hline \multirow[t]{3}{*}{ in $Z-A$ test } & 2014:5 & 2013:2 & $2014: 3$ & 2012:1 & 2014:2 & 2011:3 & $2014: 3$ & 2012:5 & $2014: 2$ & 2011:3 & 2014:2 & 2012:5 & 2011:11 \\
\hline & \multicolumn{13}{|c|}{ Correlations of the profitability measures within the bank size groups and with the EONIA Midrate } \\
\hline & ROEC_R1 & $R O E R 1$ & $R O A \_R 1$ & $N I M \_R 1$ & ROEC_R2 & ROE_R2 & $R O A \_R 2$ & NIM_R2 & ROEC_R3 & $R O E \_R 3$ & $R O A \_R 3$ & NIM_R3 & EONIA \\
\hline ROEC_R1 & 1.00 & & & & & & & & & & & & \\
\hline ROE_R1 & -0.64 & 1.00 & & & & & & & & & & & \\
\hline$R O A \_R 1$ & 0.48 & 0.25 & 1.00 & & & & & & & & & & \\
\hline$N I M_{-} R 1$ & -0.37 & 0.90 & 0.52 & 1.00 & & & & & & & & & \\
\hline EONIA & -0.72 & 0.84 & 0.06 & 0.81 & & & & & & & & & \\
\hline ROEC_R2 & & & & & 1.00 & & & & & & & & \\
\hline$R O E_{-} R 2$ & & & & & -0.61 & 1.00 & & & & & & & \\
\hline$R O A_{-} R 2$ & & & & & -0.11 & 0.80 & 1.00 & & & & & & \\
\hline$N I M_{-} R 2$ & & & & & -0.49 & 0.95 & 0.85 & 1.00 & & & & & \\
\hline EONIA & & & & & -0.65 & 0.87 & 0.68 & 0.91 & & & & & \\
\hline ROEC_R3 & & & & & & & & & 1.00 & & & & \\
\hline$R O E_{-} R 3$ & & & & & & & & & -0.53 & 1.00 & & & \\
\hline$R O A \_R 3$ & & & & & & & & & -0.11 & 0.82 & 1.00 & & \\
\hline$N I M_{-} R 3$ & & & & & & & & & -0.45 & 0.94 & 0.81 & 1.00 & \\
\hline EONIA & & & & & & & & & -0.55 & 0.85 & 0.64 & 0.92 & 1.00 \\
\hline
\end{tabular}

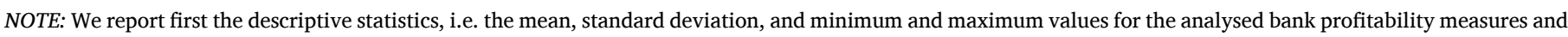

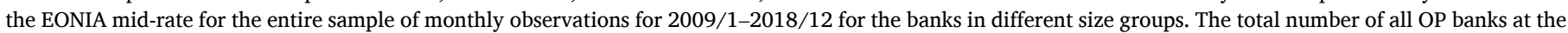

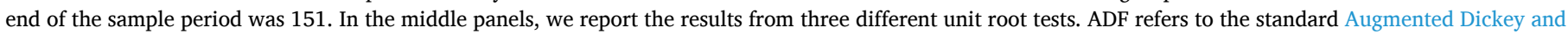

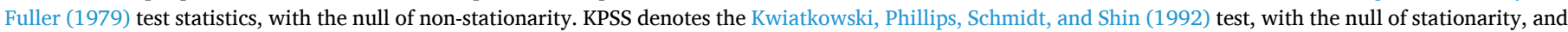

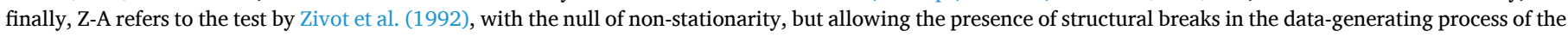

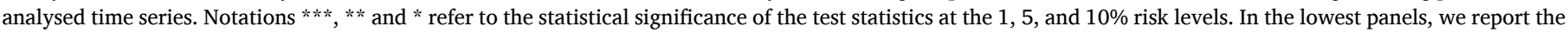

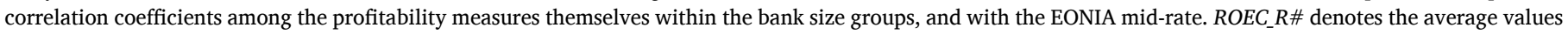

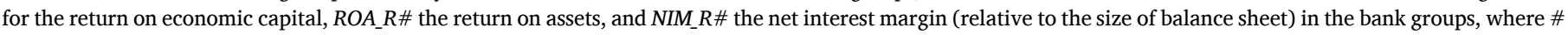
$=1,2$ or 3 . R1 refers to the group of largest banks, R2 to the medium-sized banks, and R3 to the group of smallest banks. EONIA refers to the EONIA mid-rate.

pointed out earlier, the ROE and NIM series appear to be strongly correlated, and this is also observed in the reported high correlation coefficients in Table $1 .^{21}$

However, it is also clear from a glance at the behaviour of the riskadjusted profitability measure (ROEC) in all bank size groups that it behaves clearly differently to the other standard profitability measures, such as ROA and NIM. The trend in the average ROEC values of each size group has been robustly positive until the beginning of 2018, when the OP Group Control changed some risk weights in the calculation of the EC requirement. Hence, from viewing the size group-based time series of

\footnotetext{
21 In Figs $2 a^{*}-2 c^{*}$, we also give the time-series graphs of the differenced values for all the profitability measures (excluding ROE, due to its strong correlation e.g. with NIM) and EONIA. All these series proved to be stationary in terms of differences, although, based on the various reported unit root test results, some of the analysed time series might have behaved similarly to nonstationary processes in levels. However, as we proceed with our analyses, we will use the levels of all variables because, as observed from Figs $2 a^{*}-2 c^{*}$, for example, the series on NIM and EONIA obtained a continuum of zero observations for their differenced values after 2014. This would be problematic in our analyses, because at the final stages we will be using highly advanced versions from the GARCH model family (see section 3.2), where zero observations for the analysed variables impose serious computational problems in the maximum likelihood estimations of the conditional variances and covariances.
}

the three average profitability measures it is clear, that the empirical results regarding their dynamic connections to the negative money market reference rates may also vary considerably.

The results on descriptive statistics, unit root tests, and contemporaneous correlation coefficients reported in Table 1 confirm our earlier eye-ball findings that the data-generating processes of the analysed average profitability measures indeed behave quite differently, even though by definition, based on the calculation procedures given in eqs. (1)-(7), they are also interconnected in many ways. The descriptive statistics for the NIM reveal practically no differences between the three different size groups, because the mean, standard deviation, and extreme values ( $\mathrm{min}$ and $\max$ ) are approximately the same for all groups. The same conclusion applies to the interpretation of the ROA values. The strongest differences in the descriptive statistics are observed for the ROE values, whereby the largest (R1) banks seem to have been the most profitable, but their ROE values also varied the most during the sample period. The same applies to the risk-adjusted profitability measure (ROEC), in which the variation has been the strongest for the largest banks. When interpreting the test results from the unit root analyses, we see that for the smallest banks, all four profitability measures seem to behave similarly to non-stationary processes, but this conclusion may be biased in light of the observed break in the data series, either around the beginning of 2014, or around the eurozone sovereign crisis period in 2011-2012. Even though the introduction of the endogenous structural break procedure to the unit root testing 
framework seems to result stationarity of the analysed profitability measures in many cases, it is obvious that we also have to do some analyses using the differenced values of all the variables. Finally, the preliminary (static) correlation analyses reveal that the ROE values are very strongly correlated with especially the NIM values in every size group, even more than NIM is correlated with EONIA. Hence, as already mentioned, for example, in the VAR-type analyses involving all the discussed profitability measures, we will in some cases omit the ROE from the vector of analysed variables. However, as discussed in the introduction, one of our main hypotheses is that the introduction of negative money market interest rates may have induced changes in the OP banks' business models. Hence, during the negative interest rate era, they might have increased their reliance on wholesale funding, i.e., loans from the central cooperative, and for this part of our empirical analysis, we will also introduce ROE to the set of profitability measures. Furthermore, in the final, pairwise dynamic conditional correlation analysis we will use the ROE values, too, to give a full picture of the interrelationships between the variables.

\subsection{Empirical strategy}

Based on the unit root test results reported in the previous subsection, we opted to use all the analysed time series in levels in the first stage because after taking into account the possibility of structural breaks in the form of Zivot and Andrews (1992) test, almost all the series seem to be stationary at least at $10 \%$ risk level. ${ }^{22}$ Put it more precisely, in all cases for the ROEC and ROA series in all bank size groups, the break point seemed to be in connection to the extremely low, and ultimately negative money market reference rates. Furthermore, the dramatic decrease of EONIA in November 2011 and of the Euribor rates at varying maturities within a few months subsequently might have caused a structural break to the average NIM of all bank size groups between January 2012 and May 2012. As already mentioned, our final modelling procedure, i.e., the application of one form of asymmetric, regimedependent dynamic conditional correlation (DCC- GARCH) models, requires that the analysed time series do not contain an excess of zero observations, which would basically wipe out all dynamics in the variances and particularly in covariances of the analysed series. Hence, after the standard VAR and Granger causality analyses, we will seek the statistically best possible parametric representation of the dynamic relationships between the analysed variables based on the following empirical idea.

Our methodology in modelling DCC-GARCH connections between the various bank profitability measures and the other relevant variables assumed to have affected them (i.e., the money market (EONIA) interest rate and the wholesale funding (WSF) ratio) was as follows. We estimate the time-varying covariance structures using the asymmetric generalized DCC-(AGDCC) model by Cappiello, Engle, and Sheppard (2006). To keep the number of parameters tractable, instead of using e.g. VARspecifications for the mean equations, we estimate pairwise models between a set of all four profitability measures (ROEC, ROA, ROE, and NIM) and the EONIA mid-rate or wholesale funding ratio (WSF). Because we use pairwise analyses at this final stage, our results are not biased for example by the high correlation of ROE series with the other profitability measures. The mean values of the analysed time series are modelled as.

\footnotetext{
22 Based on the ADF and KPSS-tests, the EONIA midrate is actually already stationary before any structural break tests have been applied, so as observed from Table 1 , the $Z$-A test is unable even to detect a statistically significant break point for it. However, for R3 banks, the ROA and ROE series seemed to behave as unit root processes, even when taking into account the structural breaks, so we will conduct our first stage analyses for the multivariate models also using differenced time series for all group sizes and variables (see Figs $2 a^{*}-2 c^{*}$ for the time series of differenced values).
}

$r_{i, t}=\alpha_{i}+e_{i, t}, i=1,2$

where $r_{1, t}$ is always alternatively ROEC_R1, ROEC_R2, ROEC_R3, ROE_R1, ROE_R2, ROE_R3, ROA_R1, ROA_R2, ROA_R3, NIM_R1, NIM_R2, or NIM_R3, and $r_{2, t}$ is always either the EONIA Mid-rate or WSF. Parameter $\alpha_{i}$ denotes the constant term in the mean equation, and the vector of residuals follows an $\mathrm{N}\left(0, H_{t}\right)$ distribution, where the conditional covariance matrix is decomposed based on.

$H_{t}=D_{t} R_{t} D_{t}$

and $D_{t}$ is a $2 \times 2$ diagonal matrix of conditional standard deviations

$\varepsilon_{i, t}=e_{i, t} / \sqrt{h_{i, t}}$.

We estimate $h_{i, t}$ from univariate GJR-GARCH(1,1) model (see Glosten, Jagannathan, \& Runkle, 1993) as

$h_{i, t}=\beta_{i, o}+\beta_{i, 1} e_{i, t-1}^{2}+\beta_{i, 2} h_{i, t-1}+\beta_{i, 3} I\left(e_{i, t-1}>0\right) e_{i, t-1}^{2}$,

where $\beta_{i, j}$ are the constant coefficients to be estimated and $I\left(e_{i, t-h}>0\right)$ is an indicator function, which is equal to 1 if the condition is met and zero otherwise. $R_{t}$ is the time-varying correlation matrix defined as.

$R_{t}=Q_{t}^{*-1} Q_{t} Q_{t}^{*-1}$,

where

$Q_{t}=(\bar{Q}-a \bar{Q}-b \bar{Q} B-c \bar{N})+a \varepsilon_{t-1} \varepsilon_{t-1}^{\prime}+b Q_{t-1}+c n_{t-1} n_{t-1}^{\prime}$,

and $\bar{Q}$ is the unconditional covariance matrix of the standardized residuals based on eq. (10), and $a, b$, and $c$ are scalar parameters. $\bar{N}$ refers to the unconditional covariance matrix of the standardized residuals, satisfying condition.

$n_{i, t}=\left\{\begin{array}{c}\varepsilon_{i, t} \text { if } \varepsilon_{i, t}<0 \\ 0, \text { if } \varepsilon_{i, t} \geq 0\end{array}\right.$

for all variables expect the risk-adjusted profitability measures of ROEC_R1, ROEC_R2, and ROEC_R3, for which the conditions are

$n_{i, t}=\left\{\begin{array}{l}\varepsilon_{i, t} \text { if } \varepsilon_{i, t}>0 \\ 0, \text { if } \varepsilon_{i, t} \leq 0 .\end{array}\right.$

This ensures that $\beta_{i, 3} \geq 0$ in the conditional covariance matrix (11), which is unnecessary but makes the interpretation of stationarity conditions for the conditional covariances more straightforward. Finally, we estimate the models in three stages, as suggested by Cappiello et al. (2006), and force the GARCH parameters to satisfy the conventional stationarity and non-negativity conditions.

$\beta_{i, j} \geq 0(\mathrm{j}=0,2), \beta_{i, 1}+\beta_{i, 2}+\frac{\beta_{i, 3}}{2} \leq 1$

\section{Results}

\subsection{Dynamic relationships between the profitability measures and EONIA}

Tables 2a and 2b report the results from the standard linear Granger causality tests for the levels (Table $2 \mathrm{a}$ ) and differences (Table 2b) of alternative bank profitability measures. In adopting a special focus on the money market interest rate's effects on profitability, we see that the levels of EONIA mid-rate seem to affect (Granger cause) NIM in all banks of different sizes, but that in all other respects the results vary between the different size groups. It seems that EONIA affects the risk-adjusted ROEC profitability only in the smallest R3 banks, and not at all in the larger banks, and this holds particularly during the negative interest rate period. Although EONIA clearly has a very strong causal relationship 
Table 2a

Results from Granger causality tests for the levels of alternative bank profitability measures.

\begin{tabular}{|c|c|c|c|c|c|c|c|c|c|}
\hline \multirow[b]{3}{*}{$\begin{array}{l}\text { Dependent }(Y) / \\
\text { Independent }(X)\end{array}$} & \multicolumn{9}{|l|}{ Sample } \\
\hline & \multicolumn{3}{|c|}{ Whole sample } & \multicolumn{3}{|c|}{ Sub-sample 2009:1-2014:10 } & \multicolumn{3}{|c|}{ Sub-sample 2014:11-2018:12 } \\
\hline & $R O E C_{t}$ & $R O A_{t}$ & $N I M_{t}$ & $R O E C_{t}$ & $R O A_{t}$ & $N I M_{t}$ & $R O E C_{t}$ & $R O A_{t}$ & $N I M_{t}$ \\
\hline \multicolumn{10}{|l|}{ R1 Banks } \\
\hline No GC from ROEC & - & 0.39 & 0.22 & - & $3.50 * *$ & $2.76^{*}$ & - & 0.90 & 0.54 \\
\hline No GC from $R O A$ & $17.08 * * *$ & - & $7.05^{* * *}$ & $19.13 * * *$ & - & $7.00 * * *$ & $3.23^{* *}$ & - & $2.47^{*}$ \\
\hline No GC from NIM & $10.35^{* * *}$ & $15.02^{* * *}$ & - & $14.89^{* * *}$ & $13.31^{* * *}$ & - & $2.82 *$ & $8.16^{* * *}$ & - \\
\hline No GC from EONIA & 0.04 & $7.24 * * *$ & $7.97 * * *$ & 0.09 & $6.82^{* * *}$ & $6.31 * * *$ & 2.02 & $3.75^{* *}$ & $3.92^{* * *}$ \\
\hline MVARCH & $181.79 * * *$ & & & $212.85^{* * *}$ & & & 281.61 & & \\
\hline \multicolumn{10}{|l|}{ R2 Banks } \\
\hline No GC from ROEC & - & 0.38 & 0.11 & - & 0.22 & 0.08 & - & 0.33 & 0.21 \\
\hline No GC from $R O A$ & $10.27^{* * *}$ & - & 1.41 & $11.03^{* * *}$ & - & 0.96 & $2.99 *$ & - & 0.53 \\
\hline No GC from NIM & $8.56^{* * *}$ & $10.65^{* * *}$ & - & $9.78 * * *$ & $3.54 * *$ & - & 2.36 & $7.04 * * *$ & - \\
\hline No GC from EONIA & 0.19 & $13.12^{* * *}$ & $11.75^{* * *}$ & 1.12 & $6.57^{* * *}$ & $5.67^{* * *}$ & $2.53 *$ & $4.60^{* *}$ & $4.79 * *$ \\
\hline MVARCH & $145.92 * * *$ & & & $168.07 * * *$ & & & $221.27^{* * *}$ & & \\
\hline \multicolumn{10}{|l|}{ R3 Banks } \\
\hline No GC from ROEC & - & 0.59 & 0.30 & - & 0.07 & 0.01 & - & 1.95 & 1.71 \\
\hline No GC from $R O A$ & $7.33^{* * *}$ & - & $2.55^{*}$ & $4.85^{* *}$ & - & 1.75 & $3.71^{* *}$ & - & 0.07 \\
\hline No GC from NIM & $7.23^{* * *}$ & $7.62^{* * *}$ & - & $5.37^{* * *}$ & 2.24 & - & $3.41^{* *}$ & $13.76^{* * *}$ & - \\
\hline No GC from EONIA & $0.32^{* * *}$ & $8.68^{* * *}$ & $7.38^{* * *}$ & 0.91 & $2.91^{*}$ & 2.32 & $3.69 * *$ & $6.57 * * *$ & $6.62 * * *$ \\
\hline MVARCH & 111.49 & & & $126.00 * *$ & & & $100.00 * * *$ & & \\
\hline
\end{tabular}

NOTES: We report the Granger causality test statistics based on a VAR(2) model for the bank profitability measures and the EONIA mid-rate. The EONIA was introduced as a prominently endogenous variable to the VAR system in this case. The optimal lag length (2) was chosen based on the multivariate Bayesian Schwarz criterion. The subsamples were based on dividing the total sample by two, where the critical change point was the month in which the EONIA mid-rate went negative, i.e. November 2014. Notations $* * * * *$ and * refer to the statistical significance of the F-tests at the 1,5 , and $10 \%$ risk levels, where the null hypothesis is that the independent variable $(X)$ in question does not Granger cause (denoted $G C$ ) the dependent variable $(Y)$ observed at time point $t$. For the sake of clarity of the results, we do not report the F-test statistics for the effects of own lags of each of the independent variables, because we are more interested in the dynamic connections between the various profitability measures and EONIA. ROEC denotes the return on economic capital, ROA the return on assets, and NIM refers to the net interest margin (relative to the size of balance sheet). We also report the multivariate (MVARCH)-test of Hacker and Hatemi-J (2005) indicating the possible presence of at least some form of (general) autoregressive conditional heteroscedasticity (i.e., of (G)ARCH-type) in the residuals of the dynamic relationships between the analysed variables based on the estimated VAR-model. Here, $* * * * *$ and * also refer to the statistical significance of the test-statistics at the 1,5 , and $10 \%$ risk levels, for the null of no ARCH-effects in the residuals.

Table 2b

Results from VAR-estimation for the differenced values of alternative bank profitability measures.

\begin{tabular}{|c|c|c|c|c|c|c|c|c|c|}
\hline \multirow[b]{3}{*}{$\begin{array}{l}\text { Dependent/ } \\
\text { Independent variables }\end{array}$} & \multicolumn{9}{|l|}{ Sample } \\
\hline & \multicolumn{3}{|c|}{ Whole sample } & \multicolumn{3}{|c|}{ Sub-sample 2009:1-2014:10 } & \multicolumn{3}{|c|}{ Sub-sample 2014:11-2018:12 } \\
\hline & $D R O E C_{t}$ & $D R O A_{t}$ & $\operatorname{DNIM}_{t}$ & $D R O E C_{t}$ & $D R O A_{t}$ & $D_{N I M}$ & $D R O E C_{t}$ & $D R O A_{t}$ & $D N I M_{t}$ \\
\hline \multicolumn{10}{|l|}{ R1 Banks } \\
\hline$D R O E C_{t-1}$ & $0.17^{*}$ & 0.00 & 0.00 & 0.06 & -0.00 & 0.00 & 0.10 & -0.00 & -0.00 \\
\hline$D_{R O A} A_{t-1}$ & -11.82 & $-1.72^{* * *}$ & $-0.22^{* * *}$ & $-22.10^{* * *}$ & $-2.22^{* * *}$ & $-0.26^{* * *}$ & 36.97 & 0.41 & -0.04 \\
\hline$D_{N I M}$ & 109.42 & $14.64^{* * *}$ & $2.16^{* * * *}$ & $261.71^{* * *}$ & $21.19^{* * *}$ & $2.72^{* * *}$ & $-581.03^{*}$ & $-13.98^{*}$ & -0.21 \\
\hline EONIA $_{t-1}$ & -0.11 & 0.01 & 0.00 & $-0.45^{*}$ & -0.01 & -0.00 & 0.10 & -0.02 & -0.00 \\
\hline \# of obs. & 118 & 118 & 118 & 68 & 68 & 68 & 50 & 50 & 50 \\
\hline \multicolumn{10}{|l|}{ R2 Banks } \\
\hline$D R O E C_{t-1}$ & 0.07 & 0.00 & 0.00 & 0.16 & 0.00 & 0.00 & -0.04 & -0.00 & -0.00 \\
\hline$D R O A_{t-1}$ & -9.80 & $-1.65^{* * *}$ & $-0.22^{* * *}$ & $-16.57^{* *}$ & $-1.86^{* * *}$ & $-0.23^{* * *}$ & 22.51 & 0.07 & -0.07 \\
\hline$D N I M_{t-1}$ & 81.74 & $13.51^{* * *}$ & $2.06^{* * * *}$ & $177.18^{* *}$ & $16.67^{* * *}$ & $2.33^{* * *}$ & -361.64 & -9.66 & 0.13 \\
\hline $\begin{array}{l}\text { Exogenous } \\
\text { Constant }\end{array}$ & 0.03 & -0.00 & -0.00 & 0.19 & 0.00 & 0.00 & 0.17 & -0.01 & -0.00 \\
\hline$D R O A_{t-1}$ & -8.43 & $-1.21^{* * * *}$ & $-0.18^{* * *}$ & $-18.96^{* *}$ & $-1.56^{* * *}$ & $-0.21^{* * *}$ & 27.26 & 0.48 & -0.04 \\
\hline $\operatorname{DNIM}_{t-1}$ & 51.88 & $8.22^{* *}$ & $1.63^{* * *}$ & $193.04 * *$ & $13.09^{* * *}$ & $2.03^{* * *}$ & -427.12 & $-14.55^{* *}$ & -0.20 \\
\hline \multicolumn{10}{|l|}{ Exogenous } \\
\hline Constant & -0.00 & -0.00 & -0.00 & $0.28^{*}$ & 0.00 & 0.00 & 0.01 & $-0.02^{* *}$ & -0.00 \\
\hline EONIA $_{t-1}$ & -0.22 & 0.01 & 0.00 & $-0.58^{* *}$ & 0.00 & -0.00 & 0.07 & -0.04 & -0.00 \\
\hline \# of obs. & 118 & 118 & 118 & 68 & 68 & 68 & 50 & 50 & 50 \\
\hline
\end{tabular}

NOTES: We report the VAR-parameter estimates from OLS regressions for the alternative bank profitability measures using differenced values. For all the other notations, see Table 2a, but now DROEC denotes the difference in the return on economic capital, DROA the difference in the return on assets, and DNIM refers to the difference in net interest margin (relative to the size of balance sheet). The EONIA overnight mid-rate was now used as an exogenous variable in the regressions, because according to various unit root test results (see Table 1) it might be a stationary time series in levels. The optimal lag length (1) was again chosen based on the multivariate Bayesian Schwarz criterion. Due to the relatively large number of zero observations in NIM, the testing for (G)ARCH-effects was not possible for the VARsystems for the differenced values. 
with NIM in all banks, its changes also affect the ROEC unanimously, because NIM Granger causes the ROEC in all banks, at least for the first sub-period before the negative interest rate period. However, there is no feedback from the ROEC to NIM, and even the causality from NIM to ROEC appears to vanish for the R1 and R2 banks during the negative interest rate period (at 10\% risk level). Hence, it is clear, that the relationships between the various profitability measures and the money market interest rates have changed considerably since the introduction of negative interest rates.

Regarding the most standard overall profitability measure, ROA, it seems that NIM affects ROA in all banks and in both periods but, as already mentioned, the results in terms of ROEC being affected by NIM are clearly different. For our further analyses, it is also worth noting that, based on the Hacker and Hatemi-J (2005) multivariate GARCH-tests, in $7 / 9$ cases the variables systems would seem to contain (conditionally) heteroscedastic error terms. Clearly, these results call for deeper analyses of the dynamic relationships between the analysed profitability measures and the money market interest rate, and highlights further reasons to apply the asymmetric DCC-GARCH models in the final stage.

The results reported in Table $2 \mathrm{~b}$ follow a somewhat different modelling principle compared to the standard Granger causality results reported in Table 2a. In Table 2b, we report the actual parameter estimates from VAR models estimated for the systems of profitability variables using differenced values. Based on Schwarz's Bayesian information criteria, the optimal lag length of the VAR models was 1 for each case. We report the parameter estimates for the first lag of the independent variables in each VAR-equation, and we always included the lagged values of the EONIA mid-rate (in levels ${ }^{23}$ ) and the constant term as additional exogenous regressors ${ }^{24}$ to each of the VAR systems. Hence, here we wish to particularly emphasize the role of money market interest rate in affecting each of the analysed profitability measures.

The results reported in Table $2 b$ have significantly different implications for the dynamic relationships between the bank profitability measures and the money market interest rate. The main message seems to be that the introduction of negative interest rates has wiped out all dynamic connections between the main relevant profitability measures, when we analyse the variables in differences, i.e., monthly changes in the observations. Only in the data from before the negative interest rate period do we find a statistically significant (positive) connection between the NIM and the other profitability measures, ROEC, and ROA. However, this holds for all banks' sizes and, based on the parameter estimates, the most significant results are for the largest banks, where a one basis point positive change in the NIM in the previous period appears to cause a $2.61 \%(0.21 \%)$ improvement in the ROEC (ROA) in the next period. Furthermore, past changes in the money market interest rate do not seem to play any role in changes to profitability, either before the negative interest rate period or during it, when we use a monthly frequency. In general terms, the negative interest rate era clearly seems to have affected the dynamic relationships between the main profitability measures, and their connection to money market interest rates and, to reveal the time-varying nature of these changes at the final stage, we report the results based on the dynamic conditional correlation analyses of these variables. At first, we will examine the results with respect to the role of changes in the business model, measured based on the ratio of WSF in the banks.

\footnotetext{
23 As was pointed out in the results reported in Table 1 , the EONIA midrate seems to have behaved as a stationary variable already in levels, so it was also included in levels of the analyses reported in Table $2 \mathrm{~b}$.

${ }^{24}$ Clearly, the EONIA midrate should be considered exogenously determined in all our analyses, because it is highly unlikely that any of the eurozone-level money market interest rates would react to the profitability of Finnish OP banks by any means.
}

4.2. Results on the dependence between the profitability measures and the business model measure

In Table 3 we report the results from the Granger causality analysis focusing on the relationship between bank profitability measures and the WSF ratio, i.e. from the perspective of whether the banks might have changed their business models in response to the introduction of negative interest rates. At this stage, we executed the estimations using all three profitability measures (ROEC, ROE and ROA) separately, but always including the NIM, due to its major role as the standard 'profitmaking machine' of a bank, which is also most significantly affected by the market interest rates. Furthermore, to highlight the prominent role of the bank's business model, we also always include the WSF ratio to the VAR-model. Additionally, as in Table 2b, the EONIA is always treated as an exogenous variable. We conduct all analysis for the variables in levels and separately for the periods before and after the introduction of negative interest rates.

From the results in Table 3, we see that first, the role of rising values of EONIA in positively affecting the NIM in all banks is clear during the 'normal' period of positive money market interest rates. When the EONIA increases, the contemporaneous NIMs also increase in a way that is statistically significant (and by the same amount) in all banks. However, even this result is valid for all bank size groups only when the riskadjusted profitability ROEC is used as the profitability measure. When any of the non-risk-adjusted measures are used, the positive dynamic effect from past EONIA values is observed only for R2 banks and only when ROA is used as the profitability indicator before the negative interest rate period. This highlights one of our new findings that it is essential to analyse bank profitability using both risk-adjusted and standard profitability measures.

Furthermore, an extremely interesting finding to emerge from these results is that, during the negative interest rate period, in the smaller banks (R2 and R3), the NIM has a much stronger (positive) connection to the EONIA, and this finding is not at all dependent on the measure of profitability. The effects of changes in EONIA on NIM have been approximately three times higher in R2 and R3 banks during the era of negative interest rates. Hence, when the market interest rates have risen (fallen), the NIM in R2 and R3 banks has improved (worsened) approximately three times more than during the positive interest rate era, and this finding is statistically significant at the $1 \%$ risk level. Additionally, the effect of EONIA on all profitability measures is also evident in smaller banks during the NIRP, but not during 'normal' times. However, in the big (R1) banks, EONIA has statistically significant effects only on the NIM and only during the 'normal' times, and not on any of the profitability measures (ROEC, ROE or ROA) at any time. This is also remarkably different compared to the smaller banks.

As observed in Fig. 2, NIM volatility has almost reached zero during the negative interest rate period. However, it still appears to have played a significant role in particularly affecting the smaller banks' profitability, at least in terms of ROE and ROA during the negative interest rate era. A somewhat confusing result that might have something to do with the close-to-zero volatility of the NIM during the negative interest rate period is that the dynamic effect of increasing NIM values in the most recent (two months) past has been negative, i.e., when the NIM has previously increased, the profitability of R2 and R3 banks, in particular, has subsequently decreased. Clearly, this result merits further scrutiny through the discussion of the effects and role of WSF ratio because it has increased during the negative interest rate era, particularly in R1 banks. As can be seen from Fig. 3 below, the WSF ratio actually began to increase significantly from mid-2012 in all the three bank size groups, but in R2 and R3 banks it has remained more or less stable since 2016, even though it continued its rapid growth in the biggest (R1) banks.

Obviously, the previous results and the strong dependence of NIM on the development of EONIA requires the analysis of the role of banks' business model, i.e., the effects of WSF ratio. From the Granger causality test results reported in Table 3, we see that first, for the largest R1 banks 
Table 3

Results from Granger causality tests for the alternative bank profitability measures (ROEC, ROE and ROA), including net interest margin (NIM) and wholesale funding (WSF) ratio as endogenous variables to the systems, and EONIA midrate and constant as exogenous variables. Each profitability measure is analysed individually so, for example, the system for ROEC does not include ROE or ROA at all.

\begin{tabular}{|c|c|c|c|c|c|c|c|c|c|c|}
\hline \multirow[b]{2}{*}{$\begin{array}{l}\text { Dependent }(Y) / \text { Independent } \\
(X)\end{array}$} & \multicolumn{5}{|c|}{ Sub-sample 2009:1-2014:10 } & \multicolumn{5}{|c|}{ Sub-sample 2014:11-2018:12 } \\
\hline & $R O E C_{t}$ & $R O E_{t}$ & $R O A_{t}$ & NIM $_{t}$ & $W S F_{t}$ & $R O E C_{t}$ & $R O E_{t}$ & $R O A_{t}$ & $N I M_{t}$ & $W S F_{t}$ \\
\hline \multicolumn{11}{|l|}{ R1 Banks } \\
\hline No GC from ROEC & $97.29 * * *$ & - & - & 0.120 & 0.65 & $37.73^{* * *}$ & - & - & 0.59 & $4.23^{* *}$ \\
\hline No GC from NIM & 0.99 & - & - & $64.91 * * *$ & $4.10 * *(-)$ & $\begin{array}{l}6.02^{* * *} \\
(-)\end{array}$ & - & - & $8.66^{* * *}$ & $2.73 *(-)$ \\
\hline No GC from WSF & $5.65^{* * *}(+)$ & - & - & $2.93 *(+)$ & $86.27 * *$ & $3.33^{* *}(-)$ & - & - & 0.14 & $2.96^{*}$ \\
\hline Constant & -0.94 & - & - & 0.01 & 1.06 & 19.88 & - & - & 0.05 & $27.83^{* * *}$ \\
\hline EONIA & -0.56 & - & - & $0.01 * * *$ & $-1.17 * *$ & 0.96 & - & - & 0.01 & 0.56 \\
\hline No GC from ROE & - & 1.82 & - & $4.39 * *(-)$ & $\begin{array}{l}7.96^{* * *} \\
(+)\end{array}$ & - & $70.71 * *$ & - & 0.31 & 0.56 \\
\hline No GC from NIM & - & 1.19 & - & $20.00^{* * * *}$ & $\begin{array}{l}7.70 * * * \\
(-)\end{array}$ & - & 1.69 & - & $19.04 * * *$ & 0.19 \\
\hline No GC from WSF & - & 1.62 & - & $2.56 *(+)$ & $10.89 * * *$ & - & 0.01 & - & 0.07 & $9.36^{* * *}$ \\
\hline Constant & - & 0.77 & - & 0.78 & 0.41 & - & 1.07 & - & 0.02 & 8.61 \\
\hline EONIA & - & 0.13 & - & 0.13 & $-0.88^{*}$ & - & 0.04 & - & 0.01 & 0.57 \\
\hline No GC from $R O A$ & - & - & $20.64 * * *$ & $3.64 * *(+)$ & 0.23 & - & - & $32.84^{* * *}$ & 1.85 & 1.91 \\
\hline No GC from NIM & - & - & 2.06 & $15.18^{* * *}$ & 0.06 & - & - & $\begin{array}{l}5.17 * * * \\
(-)\end{array}$ & $11.62^{* * *}$ & 0.73 \\
\hline No GC from WSF & - & - & 1.00 & 1.06 & $78.25^{* * *}$ & - & - & 0.11 & 0.14 & $3.57^{* *}$ \\
\hline Constant & - & - & -0.06 & -0.00 & 0.95 & - & - & $0.53^{* *}$ & $0.05^{* *}$ & 6.57 \\
\hline EONIA & - & - & $0.07^{*}$ & $0.01^{*}$ & $-1.11^{*}$ & - & - & 0.15 & 0.01 & -5.48 \\
\hline \multicolumn{11}{|l|}{ R2 Banks } \\
\hline No GC from ROEC & $176.84 * * *$ & - & - & 0.22 & 1.20 & $47.80 * * *$ & - & - & 1.31 & 0.20 \\
\hline No GC from NIM & 1.08 & - & - & $178.92^{* * *}$ & 1.25 & $3.20 *(-)$ & - & - & $8.40^{* * *}$ & 1.60 \\
\hline No GC from WSF & 1.44 & - & - & $5.00 * * *(+)$ & $23.74 * * *$ & 1.78 & - & - & 1.74 & 1.02 \\
\hline Constant & 0.73 & - & - & 0.01 & 1.76 & 13.81 & - & - & $0.05^{* * *}$ & 1.86 \\
\hline EONIA & -0.22 & - & - & $0.01^{* * *}$ & -0.10 & $9.23 *$ & - & - & $0.03^{* * *}$ & $-3.36^{*}$ \\
\hline No GC from ROE & - & 1.43 & - & 2.24 & 0.67 & - & $41.03^{* * *}$ & - & 0.44 & 0.63 \\
\hline No GC from NIM & - & 1.51 & - & $18.08^{* * * *}$ & 0.75 & - & $\begin{array}{l}3.37^{* * *} \\
(-)\end{array}$ & - & $6.62^{* * *}$ & 1.87 \\
\hline No GC from WSF & - & $\begin{array}{l}5.02 * * * \\
(+)\end{array}$ & - & $5.41^{* * *}(+)$ & $18.31^{* * *}$ & - & 1.93 & - & 1.22 & 0.64 \\
\hline Constant & - & 1.12 & - & 0.01 & 0.59 & - & 1.69 & - & $0.04 *$ & 4.48 \\
\hline EONIA & - & 0.38 & - & 0.01 & -0.18 & - & $1.64 * *$ & - & $0.03 * *$ & -2.08 \\
\hline No GC from $R O A$ & - & - & $14.26^{* * *}$ & 0.27 & 1.01 & - & - & $32.59 * * *$ & $\begin{array}{l}3.36 * * \\
(-)\end{array}$ & 1.40 \\
\hline No GC from NIM & - & - & 0.88 & $29.96^{* * *}$ & 0.96 & - & - & $3.56^{* *}(-)$ & $12.41^{* * *}$ & 0.46 \\
\hline No GC from WSF & - & - & $\begin{array}{l}3.90 * * \\
(+)\end{array}$ & $3.93^{* *}(+)$ & $18.31^{* * *}$ & - & - & $3.05 *(+)$ & $2.82 *(+)$ & 0.06 \\
\hline Constant & - & - & 0.01 & 0.00 & 0.79 & - & - & 0.41 & $0.04 *$ & 5.80 \\
\hline EONIA & - & - & $0.13^{* * *}$ & $0.10 * * *$ & -0.19 & - & - & $0.30 * * *$ & $0.03^{* * *}$ & $-2.94 *$ \\
\hline & \multicolumn{5}{|c|}{ Sub-sample 2009:1-2014:10 } & \multicolumn{5}{|c|}{ Sub-sample 2014:11-2018:12 } \\
\hline $\begin{array}{l}\text { Dependent }(Y) \text { / Independent } \\
(X)\end{array}$ & $R O E C_{t}$ & $R O E_{t}$ & $R O A_{t}$ & $N I M_{t}$ & $W S F_{t}$ & $R O E C_{t}$ & $R O E_{t}$ & $R O A_{t}$ & $N I M_{t}$ & $W S F_{t}$ \\
\hline \multicolumn{11}{|l|}{ R3 Banks } \\
\hline No GC from ROEC & $332.07^{* * *}$ & - & - & 1.07 & 1.21 & $31.61^{* * *}$ & - & - & 1.90 & 1.50 \\
\hline No GC from NIM & 2.34 & - & - & $204.39 * * *$ & 1.30 & $4.27 * *(-)$ & - & - & $4.57 * *$ & 0.95 \\
\hline No GC from WSF & 2.20 & - & - & $4.93^{* *}(+)$ & $37.70^{* * *}$ & 0.35 & - & - & $2.97 *(+)$ & $9.67^{* * *}$ \\
\hline Constant & 0.90 & - & - & 0.00 & $2.65^{*}$ & $34.81^{* *}$ & - & - & $0.09 * * *$ & -2.36 \\
\hline EONIA & -0.33 & - & - & $0.01^{* * *}$ & -0.11 & $11.61^{*}$ & - & - & $0.04 * * *$ & -3.16 \\
\hline No GC from ROE & - & 1.63 & - & $6.16^{* * *}(-)$ & 1.19 & - & $71.58^{* * *}$ & - & 0.88 & $3.19 *(-)$ \\
\hline No GC from NIM & - & $4.11^{* *}(+)$ & - & $36.98^{* * *}$ & 1.42 & - & $4.71 * *(-)$ & - & $4.34 * *$ & $\begin{array}{l}3.88^{* *} \\
(+)\end{array}$ \\
\hline No GC from WSF & - & $\begin{array}{l}7.34 * * * \\
(+)\end{array}$ & - & $7.40 * * *(+)$ & $23.11^{* * *}$ & - & $4.34 * *(+)$ & - & $3.34^{* *}(+)$ & $\begin{array}{l}3.95^{* *} \\
(+)\end{array}$ \\
\hline Constant & - & 1.14 & - & $0.02 *$ & 0.73 & - & $2.66^{*}$ & - & $0.05^{* *}$ & 3.07 \\
\hline EONIA & - & -0.07 & - & -0.00 & 0.35 & - & $1.89 * * *$ & - & $0.03^{* * *}$ & -2.07 \\
\hline No GC from ROA & - & - & $2.60 *$ & $4.86^{* * *}$ & $2.53^{*}$ & - & - & $64.85^{* * *}$ & $2.76^{*}$ & 1.65 \\
\hline No GC from NIM & - & - & 2.30 & $44.83^{* * *}$ & $2.93^{*}$ & - & - & $6.62^{* * *}(-)$ & $\begin{array}{l}5.91^{* * *} \\
(+)\end{array}$ & $2.46 *(+)$ \\
\hline
\end{tabular}


Table 3 (continued)

\begin{tabular}{|c|c|c|c|c|c|c|c|c|c|c|}
\hline \multirow[b]{2}{*}{$\begin{array}{l}\text { Dependent }(Y) / \text { Independent } \\
(X)\end{array}$} & \multicolumn{5}{|c|}{ Sub-sample 2009:1-2014:10 } & \multicolumn{5}{|c|}{ Sub-sample 2014:11-2018:12 } \\
\hline & $R O E C_{t}$ & $R O E_{t}$ & $R O A_{t}$ & $N I M_{t}$ & $W S F_{t}$ & $R O E C_{t}$ & $R O E_{t}$ & $R O A_{t}$ & $N I M_{t}$ & $W S F_{t}$ \\
\hline No GC from WSF & - & - & $\begin{array}{l}7.23^{* * *} \\
(+)\end{array}$ & $7.14^{* * *}$ & $11.06^{* * *}$ & - & - & $3.36 * *(+)$ & $3.45^{* *}(+)$ & $\begin{array}{l}3.73^{* *} \\
(+)\end{array}$ \\
\hline Constant & - & - & 0.05 & 0.06 & 1.16 & - & - & $0.71^{* * *}$ & $0.06^{* * *}$ & 4.59 \\
\hline EONIA & - & - & 0.03 & 0.00 & 0.31 & - & - & $0.35 * * *$ & $0.03 * * *$ & $-3.72 *$ \\
\hline
\end{tabular}

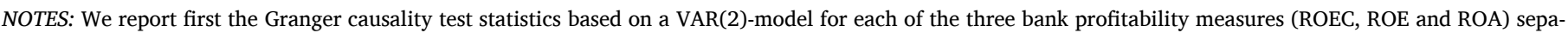

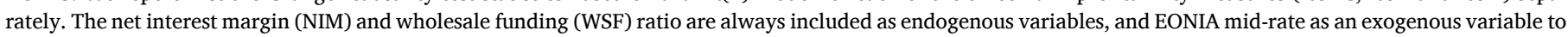

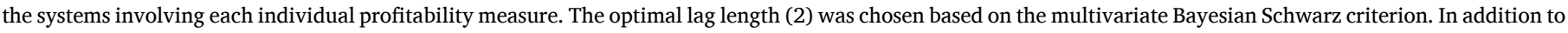

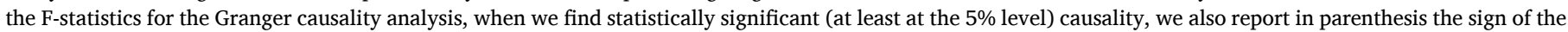

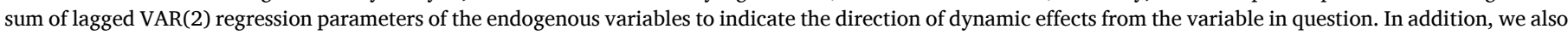

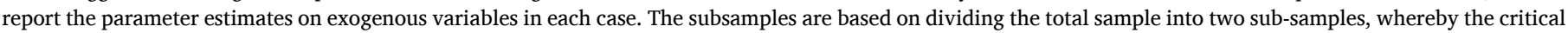

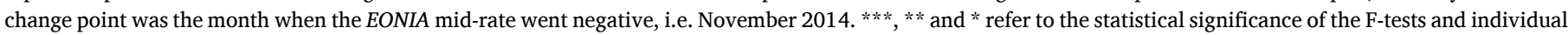

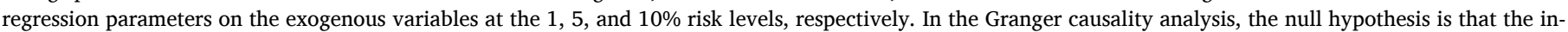
dependent variable $(X)$ in question does not Granger cause (denoted $G C$ ) the dependent variable $(Y$ ) observed at time point $t$.

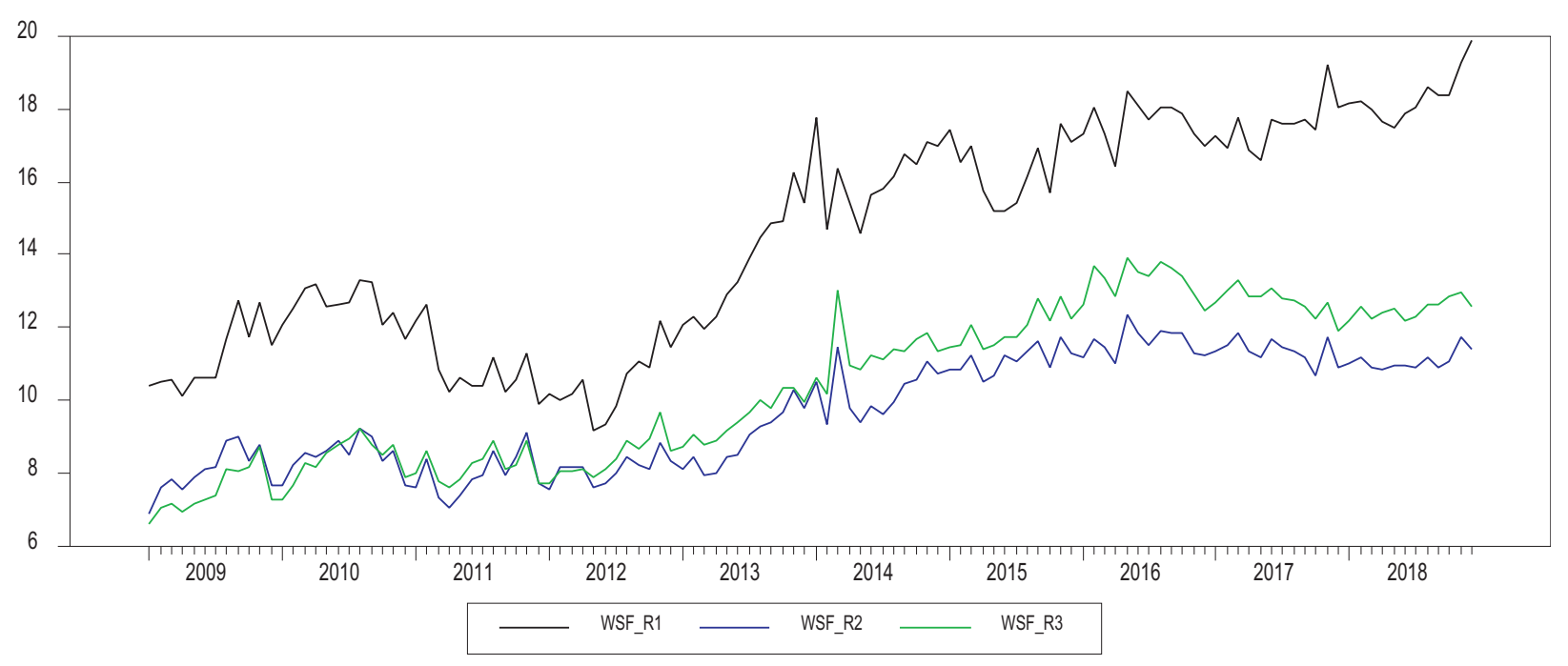

Fig. 3. Time series of wholesale funding (WSF) ratio for the banks in different bank size groups.

during the first sub-period, the increasing values of the WSF ratio in the previous two months have had a positive effect on the current, riskadjusted ROEC profitability. However, this is not the case for the other profitability measures. Furthermore, before the negative interest rate period, past increases in WSF have also improved both the ROE and ROA profitability of R2 banks, but not the risk-adjusted ROEC profitability. The same may be stated for the smallest R3 banks, i.e., their ROE and ROA profitability has improved when WSF has increased.

Some of these results change when we move to the period of negative interest rates. Namely, the positive risk-adjusted profitability reaction of $\mathrm{R} 1$ banks to positive changes in WSF becomes a negative reaction during the negative interest rate period, although none of the other profitability measures appear to react in any way. Furthermore, for the smaller R2 and R3 banks, non-risk-adjusted (ROE and ROA) profitability appears to have been in positive connection to previous increases in WSF, and this result appears to hold during the negative interest rate era, at least for the smaller R3 banks. Hence, at least based on these results, the smallest banks benefitted the most from the positive effects of increasing WSF on NIM, based on the negative interest rates that the central cooperative has charged on central bank loans taken by the smallest member banks. In general terms, this conclusion does not apply to the data from R1 banks, because the increasing WSF values do not appear to be significantly connected to the average profitability of the 23 largest banks, expect when he ROEC measure is used during the first sub-sample.

Clearly, there may be several empirical caveats in our previous analyses. The first is that we have chosen the introduction of negative money market (EONIA) interest rates in November 2014 as the break point in our data. As we have seen from the figures above, the EONIA mid-rate also experienced strong changes (lowering) in 2011-2012 around the eurozone sovereign debt crisis, so choosing the November 2014 observation as the 'main' and only structural break point might be questionable. Additionally, after the introduction of negative interest rates, the volatilities of banks' NIMs and the EONIA mid-rate have decreased significantly, so it is clear that these, and due to their interconnections to the analysed profitability measures, all the analysed time series contain volatility clustering in their data-generating processes. Furthermore, several asymmetries may be evident in the behaviour of volatilities of the analysed time series, so both the correlations and variances may have changed abruptly during our sample period. Hence, at the final stage of our empirical analysis, we use the asymmetric DCC-GARCH modelling procedure described in Section 3.2, which allows for the time-variation in the dynamic correlations (and covariances) between the variables. In this procedure, the break points in the data-generating processes of the time series are also determined endogenously.

\subsection{Results from the asymmetric DCC-GARCH analysis}

In Tables $4 \mathrm{a}$ and $4 \mathrm{~b}$ we report the results from estimating the asymmetric DCC-GARCH models given by eqs. (8), (11) and (13) in 
Table 4a

Parameter Estimates of the pairwise Asymmetric DCC-GARCH models.

\begin{tabular}{|c|c|c|c|c|c|c|c|c|c|c|c|}
\hline Variable $\backslash$ Parameter & $\alpha_{i}$ & $\beta_{i, 0}$ & $\beta_{i, 1}$ & $\beta_{i, 2}$ & $\beta_{i, 3}$ & $a$ & $b$ & $c$ & $a^{\#}$ & $b^{\#}$ & $c^{\#}$ \\
\hline \multicolumn{12}{|l|}{ Profitability Measures } \\
\hline ROEC_R1 & $27.93^{* * *}$ & 1.12 & $0.96^{* * *}$ & 0.0000 & 0.07 & $0.67 * * *$ & $0.29 *$ & -0.02 & $0.52^{* * *}$ & $0.45^{* * *}$ & -0.01 \\
\hline$R O E C_{-} R 2$ & $27.93^{* * *}$ & $1.42 * * *$ & $0.93^{* * *}$ & 0.00 & 0.05 & $0.84 * * *$ & 0.00 & 0.05 & $0.48^{* * *}$ & $0.49 * * *$ & $-0.03^{*}$ \\
\hline ROEC_R3 & $26.69 * * *$ & $1.94 *$ & $0.88^{* * *}$ & 0.0000 & 0.02 & $0.81 * * *$ & 0.03 & 0.04 & $0.57^{* * *}$ & $0.40^{* * *}$ & $-0.02 *$ \\
\hline$R O E_{-} R 1$ & $11.89 * * *$ & $0.18^{* * *}$ & $0.65^{* * *}$ & $0.18 * * *$ & $0.17^{* * *}$ & $0.51 * * *$ & $0.56^{* * *}$ & $-0.16^{* *}$ & $0.92^{* * *}$ & 0.30 & $-0.43^{* * *}$ \\
\hline$R O E_{-} R 2$ & $8.79 * * *$ & $0.06^{* * *}$ & $0.64 * * *$ & $0.24 * * *$ & $0.15^{* *}$ & $0.48 * * *$ & $0.59 * * *$ & -0.13 & $0.94 * * *$ & $0.27^{*}$ & $-0.44 * * *$ \\
\hline$R O E \_R 3$ & $7.92^{* * *}$ & $0.05^{* * *}$ & $0.59 * * *$ & $0.28 * * *$ & $0.14^{* * *}$ & $0.56^{* * *}$ & 0.34 & 0.03 & $0.69 * * *$ & $0.36^{* * *}$ & -0.15 \\
\hline$R O A_{-} R 1$ & $1.34 * * *$ & $0.02 * * *$ & $0.52^{* * *}$ & $0.24^{* * *}$ & 0.13 & $0.61 * * *$ & $0.36^{* * *}$ & -0.03 & $0.82^{* * *}$ & 0.13 & -0.08 \\
\hline$R O A \_R 2$ & $1.35^{* * *}$ & $0.01 *$ & $0.51^{* * *}$ & $0.35^{* * *}$ & 0.12 & $0.47 * * *$ & $0.52 * * *$ & -0.04 & $0.48^{* * *}$ & $0.53^{* * *}$ & -0.09 \\
\hline$R O A \_R 3$ & $1.27^{* * *}$ & $0.01^{* *}$ & $0.51^{* * *}$ & $0.33^{* * *}$ & 0.04 & $0.34 * * *$ & $0.51^{* * *}$ & 0.11 & $0.47^{* * *}$ & $0.44^{* * *}$ & 0.04 \\
\hline$N I M_{-} R 1$ & $0.11^{* * *}$ & $0.01 * * *$ & $0.65^{* * *}$ & $0.14 * *$ & 0.18 & $0.47 * * *$ & $0.40 * * * *$ & $0.11^{*}$ & $1.10^{* * *}$ & 0.03 & -0.52 \\
\hline$N I M_{-} R 2$ & $0.12^{* * *}$ & 0.0000 & $0.64 * * *$ & $0.27^{*}$ & 0.08 & $0.51^{* * *}$ & $0.39 * * *$ & 0.07 & $0.86^{* *}$ & 0.19 & -0.33 \\
\hline$N I M \_R 3$ & $0.12^{* * *}$ & 0.0000 & $0.61^{* * *}$ & $0.30 * * *$ & $0.09 *$ & $0.35^{* * *}$ & $0.54 * * *$ & $0.12^{*}$ & $0.48^{* * *}$ & $0.48^{* * *}$ & 0.02 \\
\hline \multicolumn{12}{|c|}{ Business Model Measure } \\
\hline$W S F_{-} R 1$ & $14.52^{* * *}$ & $0.80^{* *}$ & $0.59 * * *$ & $0.29 * * *$ & 0.08 & $0.57^{* * *}$ & $0.30 * * *$ & $0.12^{* * *}$ & - & - & - \\
\hline WSF_R2 & $9.72^{* * *}$ & $0.27 *$ & $0.47^{* * *}$ & $0.41 * * *$ & 0.03 & $0.61 * * *$ & $0.22 * * *$ & $0.16^{* * *}$ & - & - & - \\
\hline$W S F_{-} R 3$ & $10.42^{* * *}$ & $0.59 * * *$ & $0.54 * * *$ & $0.29 * * *$ & 0.03 & $0.53^{* * *}$ & $0.39 * * *$ & 0.07 & - & - & - \\
\hline \multicolumn{12}{|l|}{ Market Interest Rate } \\
\hline EONIA & $0.12^{* * *}$ & $0.01^{* *}$ & $0.98^{* * *}$ & 0.01 & 0.02 & - & - & - & - & - & - \\
\hline
\end{tabular}

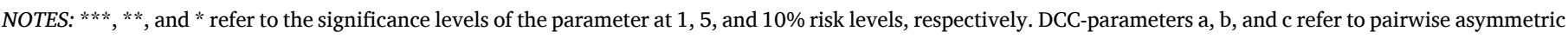

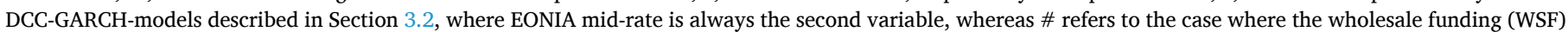

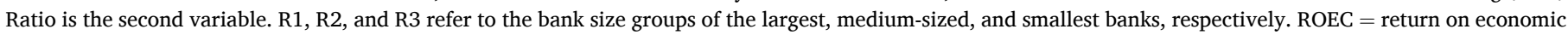

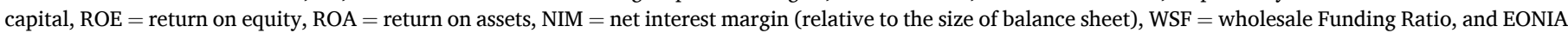
$=$ EONIA mid-rate.

Table 4b

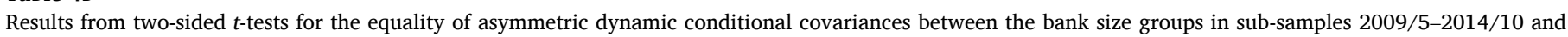
2014/11-2018/12.

\begin{tabular}{|c|c|c|c|c|c|c|c|c|c|c|c|}
\hline \multicolumn{12}{|c|}{ Covariances with EONIA mid-rate } \\
\hline \multicolumn{12}{|c|}{ Sub-sample $2009 / 5-2014 / 10$} \\
\hline & ROEC_R1 & ROEC_R2 & & ROE_R1 & ROE_R2 & & ROA_R1 & ROA_R2 & & NIM_R1 & NIM_R2 \\
\hline ROEC_R2 & $-1.71 *$ & & ROE_R2 & 0.80 & & ROA_R2 & $-3.29 * * *$ & & NIM_R2 & $-1.81^{*}$ & \\
\hline ROEC_R3 & $-2.00 * *$ & -0.30 & ROE_R3 & $2.05^{* *}$ & 1.45 & ROA_R3 & $-2.70^{* * *}$ & 1.27 & NIM_R3 & $-1.92^{*}$ & -0.19 \\
\hline \multicolumn{12}{|c|}{ Sub-sample 2014:11-2018:12 } \\
\hline & ROEC_R1 & ROEC_R2 & & ROE_R1 & ROE_R2 & & ROA_R1 & ROA_R2 & & NIM_R1 & NIM_R2 \\
\hline ROEC_R2 & $-5.72^{* * *}$ & & ROE_R2 & $2.44^{* *}$ & & ROA_R2 & $-7.28 * * *$ & & NIM_R2 & $-3.79^{* * *}$ & \\
\hline ROEC_R3 & $2.08 * *$ & -1.19 & ROE_R3 & $-4.62^{* * *}$ & $2.32^{* *}$ & ROA_R3 & $-3.73^{* * *}$ & 1.17 & NIM_R3 & $-10.69 * * *$ & -0.40 \\
\hline \multicolumn{12}{|c|}{ Covariances with wholesale funding (WSF) ratio } \\
\hline \multicolumn{12}{|c|}{ Sub-sample 2009/5-2014/10 } \\
\hline & ROEC_R1 & ROEC_R2 & & ROE_R1 & ROE_R2 & & ROA_R1 & ROA_R2 & & NIM_R1 & NIM_R2 \\
\hline ROEC_R2 & $6.07 * * *$ & & ROE_R2 & $-2.70 * * *$ & & ROA_R2 & $3.16^{* * * *}$ & & NIM_R2 & -0.54 & \\
\hline ROEC_R3 & $5.38^{* * *}$ & -0.82 & ROE_R3 & $-2.28 * *$ & 0.87 & ROA_R3 & $3.55^{* *}$ & 0.73 & NIM_R3 & 0.78 & 1.55 \\
\hline \multicolumn{12}{|c|}{ Sub-sample 2014/11-2018/12 } \\
\hline & ROEC_R1 & ROEC_R2 & & ROE_R1 & ROE_R2 & & ROA_R1 & ROA_R2 & & NIM_R1 & NIM_R2 \\
\hline ROEC_R2 & $9.15^{* * *}$ & & ROE_R2 & $-6.17^{* * *}$ & & ROA_R2 & $5.93^{* * *}$ & & NIM_R2 & $-1.70^{*}$ & \\
\hline ROEC_R3 & $20.78^{* * *}$ & -0.99 & ROE_R3 & $-2.03^{* *}$ & 1.10 & ROA_R3 & $2.75^{* * *}$ & 1.12 & NIM_R3 & $9.60^{* * *}$ & $4.37^{* * *}$ \\
\hline
\end{tabular}

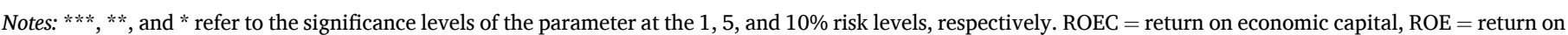

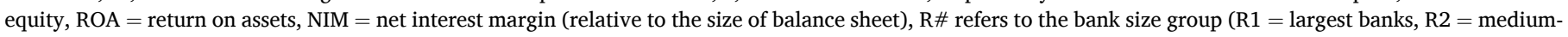
sized, and R3 = small banks).

Section 3.2. The parameter estimates and the estimated covariances are presented in Table 4a. In addition, in Table $4 \mathrm{~b}$ we report the $t$-test results from tests to determine whether the estimated dynamic conditional covariances differ among the different bank size groups, particularly during the period of negative money market interest rates compared to the previous sub-sample. Finally, the development of the time-varying pairwise covariances is given in Figs. $4 a-4 e$ and Figs. 5a-5d.

Based on our results, all the DCC parameters satisfy the stationarity conditions presented in Cappiello et al. (2006). From Table 4a we see that the parameter estimates obtained from the modelling procedure applied are valid and that the entire approach yields statistically relevant results. First, the GARCH equation has robustly significant parameter estimates, both for the effects of error terms (ARCH-part) and for the effects of variance terms (the generalized (G)ARCH-part) in all cases. ${ }^{25}$ Additionally, the asymmetric effects on the conditional variance coming from the sign of the error term in the GARCH equation (parameter $\beta_{i, 3}$ ) are statistically significant for the ROE profitability analysis, i.e. when the errors are positive, they increase the conditional

\footnotetext{
25 The conditional variance equations for the ROEC measures seem to be simple ARCH processes in each case, i.e., for all the bank size categories, and so seems to be the variance of the EONIA midrate process, too. However, for each ROEC and EONIA pair, the asymmetric effects are still evident in the covariances coming from the error terms, because the $a$ parameters are also statistically significant at the $1 \%$ risk level for the ROEC equations.
} 

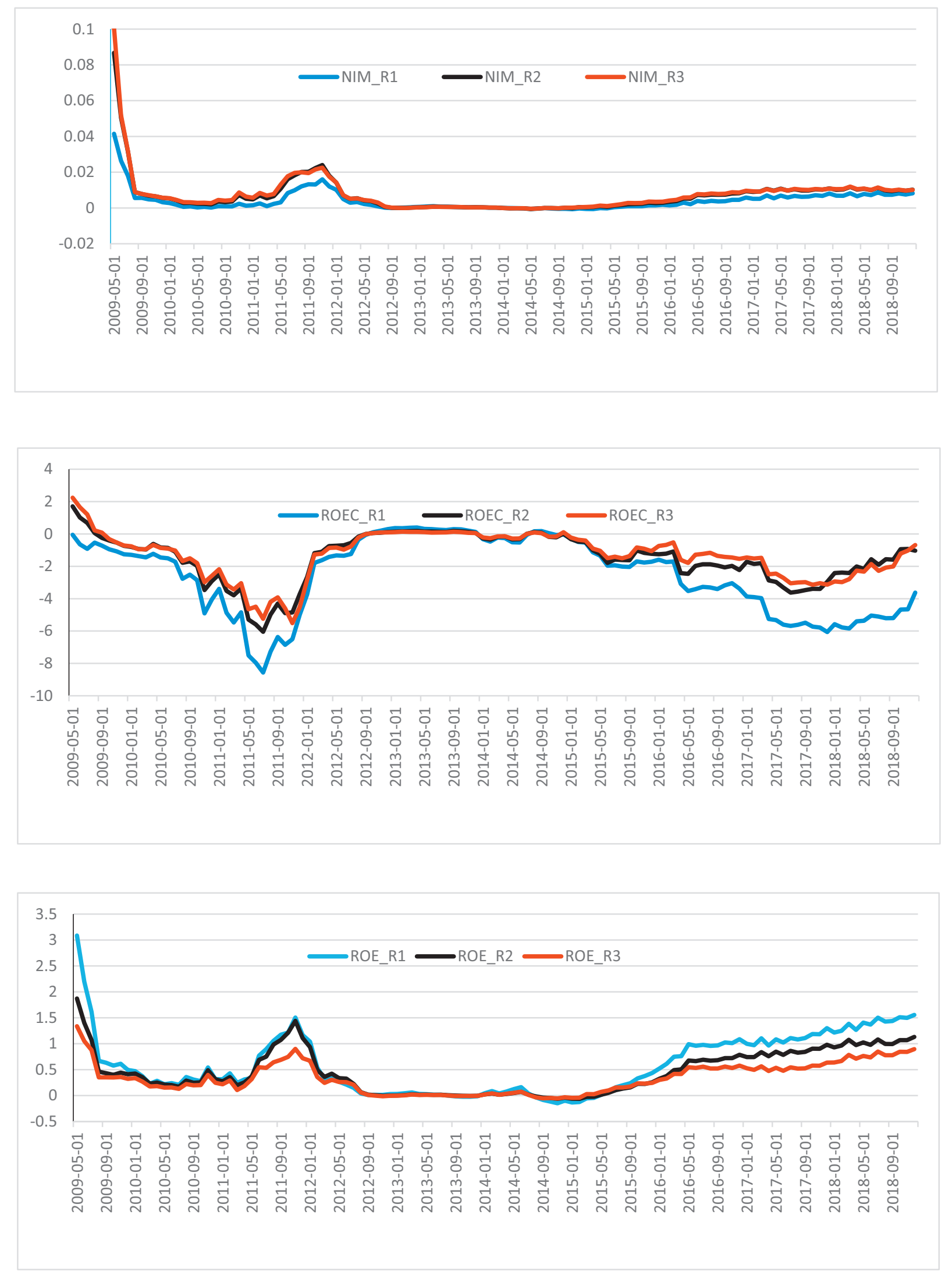

Fig. 4. a. Asymmetric DCC-GARCH covariance between net interest margin (NIM) and EONIA mid-rate in the three bank size groups. b. Asymmetric DCC-GARCH covariance between return on economic capital (ROEC) and EONIA mid-rate in the three bank size groups. c. Asymmetric DCC-GARCH covariance between return on equity (ROE) and EONIA mid-rate in the three bank size groups. d. Asymmetric DCC-GARCH covariance between return on assets (ROA) and EONIA mid-rate in the three bank size groups. e. Asymmetric DCC-GARCH covariance between wholesale funding (WSF) ratio and EONIA mid-rate in the three bank size groups. 

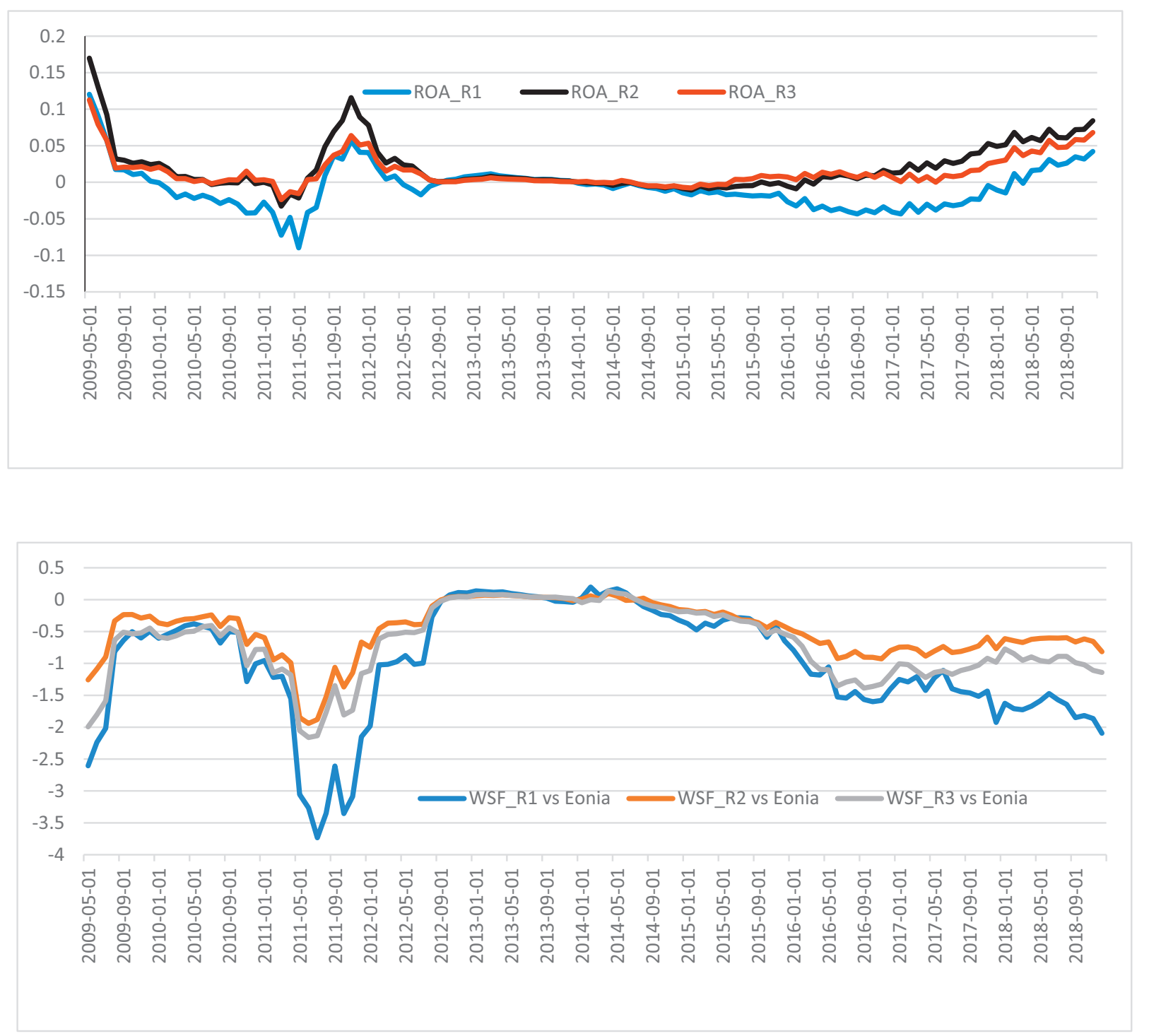

Fig. 4. (continued).

variance of profitability measured by the ROE more than when the errors are negative. In all other cases, when we analyse the dynamic timevarying correlation/covariance of the EONIA mid-rate with the profitability measures, we see that the asymmetric effects derive from asymmetry in both the error terms (reflected by the significance of $a$ parameters) and the conditional pairwise covariances (captured by the significance of $b$ parameter). However, no effects are caused by the asymmetry of correlations because the $c$ parameters are only rarely statistically significant. Additionally, it seems that when analysing the dynamic conditional covariance between EONIA and the risk-adjusted measure of profitability (ROEC), it is essential to consider the asymmetry in the GARCH error terms.

In comparing the results of the DCC analysis when using the EONIA vs. the WSF ratio in the pairwise correlation analysis, a striking difference becomes evident in the latter case. When WSF is the correlating variable, we find that the risk-adjusted profitability (ROEC) is also dynamically correlated with the WSF, when the asymmetry in conditional pairwise covariances is taken into account (cf. significance and magnitude of parameter $b^{\#}$ compared to $b$ ). In addition, when measuring the profitability by ROE, the asymmetry derived from the dynamic correlations also seems to be relevant. However, when using WSF, the asymmetry that derives from conditional pairwise covariances vanishes in the data for the R1 and R2 banks, when the NIM is the profitability measure. Hence, based on all the results reported in Table 4a, it is vital to account for major asymmetries, particularly at the level of variances between the analysed pairs of variables, and they clearly also affect the dynamic conditional covariances. Furthermore, the dynamic, timevarying dependence of various profitability measures seems to differ somewhat with respect to the EONIA mid-rate and the WSF ratio. Here, in economic terms, it is important to note that the latter variable is clearly a decisive variable upon which individual banks can decide, while the EONIA mid-rate is purely an exogenous, informative variable that must simply be taken as a given indicator of the level of market interest rates. The importance of EONIA with respect to bank profitability and WSF comes from the fact that it is strongly correlated, for example, with the main loan and deposit reference (i.e., Euribor) rates. Indeed, based on our results, the dynamic connection between probability and WSF seems to differ somewhat to its connection of EONIA. Intuitively, and in economic terms, this is clearly related to the fact that when the EONIA has entered the negative zone, the individual banks 

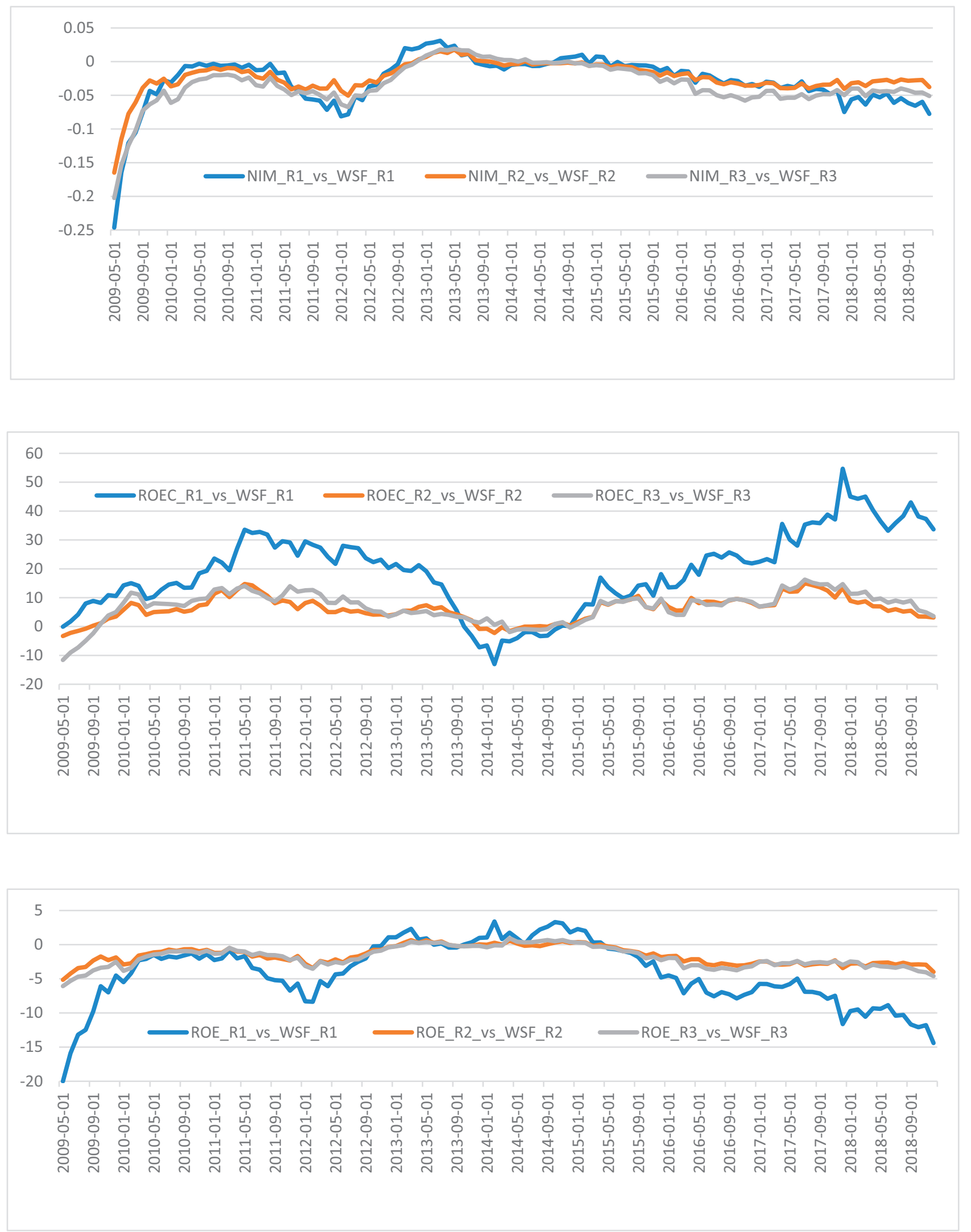

Fig. 5. a. Asymmetric DCC-GARCH covariance between net interest margin (NIM) and wholesale funding (WSF) ratio in the three bank size groups b. Asymmetric DCC-GARCH covariance between return on economic capital (ROEC) and wholesale funding (WSF) ratio in the three bank size groups. c. Asymmetric DCC-GARCH covariance between return on equity (ROE) and wholesale funding (WSF) ratio in the three bank size groups. d. Asymmetric DCC-GARCH covariance between return on assets (ROA) and wholesale funding (WSF) ratio in the three bank size groups. e. Asymmetric DCC-GARCH covariance between return on economic capital (ROEC) and return on other income components (ROIC) ratio in the three bank size groups. f. Asymmetric DCC-GARCH covariance between return on other income components (ROIC) ratio and wholesale funding ratio (WSF) in the three bank size groups. 

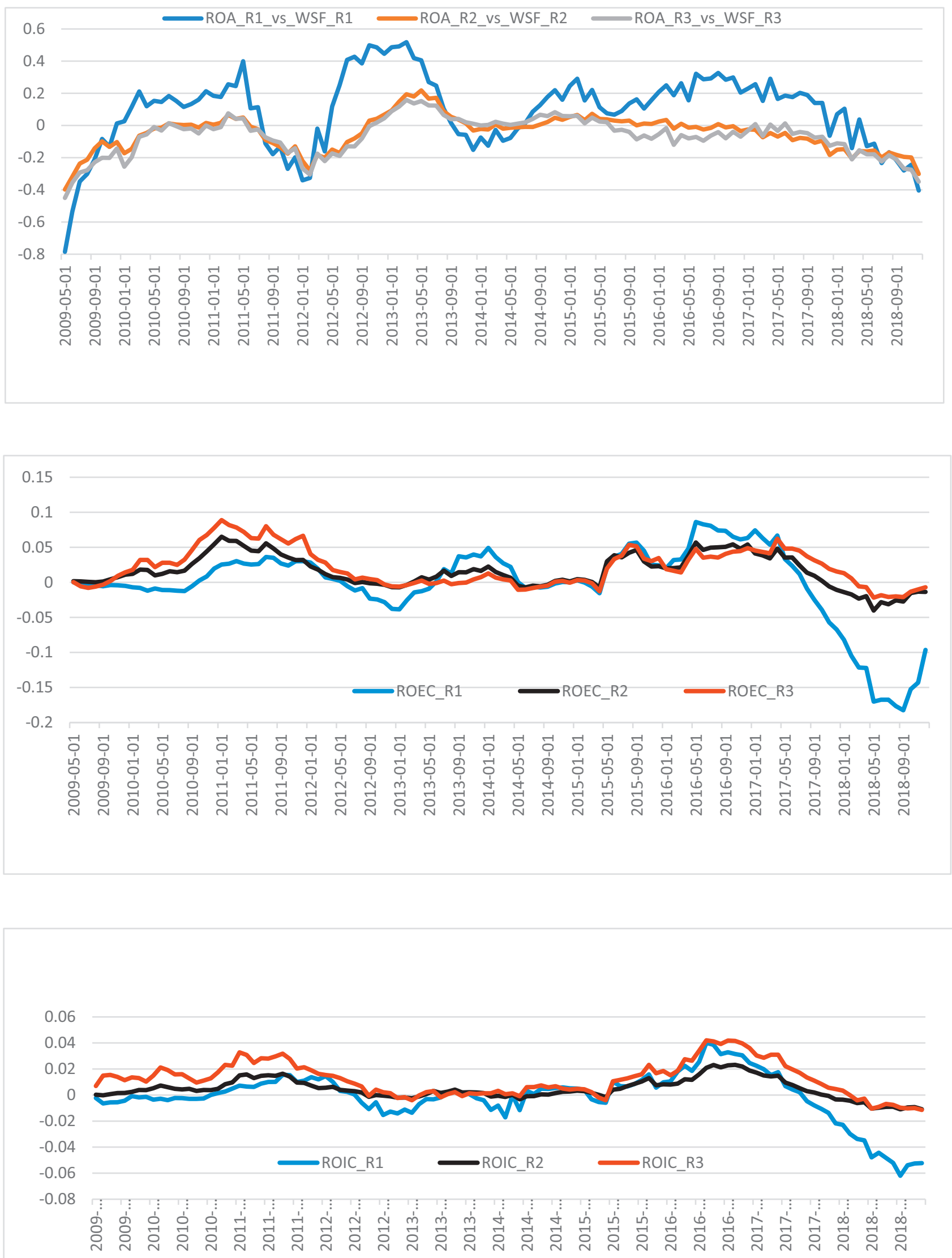

Fig. 5. (continued). 
might have increased their loans from the central cooperative, because ceteris paribus, this action has improved their NIMs. ${ }^{26}$ If this hypothesis were to hold, it would imply that WSF and EONIA should have been negatively correlated, particularly during the era of negative money market interest rates, i.e., since November 2014 in our data set.

To gain further insight into the dynamic, time-varying connections between the profitability measures and EONIA and our measure for the bank business model (WSF), first in Figs. $4 \mathrm{a}-4 \mathrm{~d}$ we examine the timevarying covariances between EONIA and profitability measures. In the next step, in Fig. 4e, we plot the dynamic conditional covariances between EONIA and WSF. Finally, in Figs. 5a-5d we plot the time series of dynamic conditional covariances between the profitability measures and WSF. This should give us the final answer to the question of whether the observed higher rate of WSF, reflecting a change in the bank business model, has affected bank profitability, and what the role of 'right' measure of profitability is in this conclusion.

Based on the time-series plots of the asymmetric dynamic conditional covariances, we obtain several interesting new results pertaining to the effects of negative interest rates on bank profitability. First, the standard textbook idea of the positive dependence of the main profitability origin of banks, the NIM, on money market interest rate also holds in our data for all three bank size categories. Hence, during the era of negative interest rates also, even though the volatilities of both the NIM in all banks and the EONIA mid-rate have been very close to zero, the dynamic conditional covariances have consistently remained positive, implying that the correlation has been positive (or very close to zero), as the standard, textbook banking theories imply, too. However, our results emphasize the importance of examining bank profitability through a much larger set of profitability measures, since the conclusions obtained are highly sensitive to the chosen profitability measures.

In focusing on the risk-adjusted (ROEC) profitability, it is clear that the significant decrease in the money market interest rates in mid-2009 has changed the relationship between ROEC and market interest rates so that the correlation between ROEC and EONIA became profoundly negative when the decline of EONIA stabilized during 2010. However, since mid-2012, the covariance was almost zero until the quotation of negative EONIA midrates began in November 2014. Subsequently, the dynamic conditional covariance path between ROEC and EONIA for the largest R1 banks has deviated significantly from the development of the smaller banks. This deviation is also statistically significant, as can be seen from the two-sided $t$-test statistics for the difference between the covariance series in the different bank size groups in Table 4b. According to these statistics, the covariance between ROEC and EONIA has been approximately equal in R2 and R3 banks for both sub-periods, but the development of the R1 group has deviated from the others, particularly since the introduction of negative money market interest rates. Hence, based on our results, the largest R1 banks, in particular, have actually improved their risk-adjusted profitability during the negative interest rate era, as the deeper in the negative zone the EONIA rate has been, the higher the ROEC profitability of the R1 banks in particular has been. However, it is worth observing that this strong negative dependence started to weaken already in the mid of 2017 in the banks of all sizes, so the continuum of extremely low and negative interest rates does not seem to benefit the banks especially in terms of the risk-adjusted profitability anymore. It is also worth noting that when the OP Group changed the weight of the interest risk component in the calculation of the requirement for EC at the beginning of 2018, it seems to have at least partly

\footnotetext{
${ }^{26}$ See also Fig 3, from which we can clearly observe that the largest (R1banks) in particular have increased their dependence on wholesale funding throughout all the years of decreasing money market interest rates, i.e., since mid-2012 already. Although, in average terms, the smaller banks generally seem to have placed a hold on this development in recent years, the largest banks have continued along the same path during the period of negative interest rates.
}

affected the change in the slope of the dynamic covariance between the ROEC and EONIA in all banks.

With respect to the more standard profitability measures (ROE and ROA), we see that analogously to the NIM covariance with EONIA, the ROE dynamic conditional covariance with EONIA remains positive throughout the whole sample but, again, the behaviour begins to differ significantly in different bank size groups after the quotation of negative market rates. As may also be seen from the results presented in Table 4b, the difference between the various bank size groups is statistically significant (at least at 5\% level) for all cases after 2014/11, but only for the pair of R1 and R3 banks before that. It seems that the ROE profitability has the strongest positive correlation with the development of EONIA in R1 banks, and the smallest in R3 banks. Hence, when the EONIA has gone deeper into the negative zone, the ROE profitability has suffered the most in R1 banks, because the dynamic asymmetric covariance is highest for them as a group. Regarding the ROA covariances with the EONIA, the result differs somewhat. Analogously to the ROEC analysis, in this case we also see a deep dive into the negative zone in covariances around 2010-2011, particularly for the R1 banks, but afterwards the covariances were approximately zero for all bank size groups until the quotation of negative money market interest rates began in 2014/11. Immediately after that, the dynamic dependence of ROA profitability on EONIA development began to deviate in R1 banks from that in both the R2 and R3 banks. More importantly, until the beginning of 2018, the covariance between ROA and EONIA for the R1 banks remained negative, but it has remained positive (and increased) towards the end of the sample for the R2 and R3 banks. This implies that were we to focus solely on the ROA profitability measure, the effect of increasingly negative money market interest rates on profitability has been improving for R1 banks (but note that only until 2018), but deteriorating for the smaller banks. Again, the differences in these dependencies are statistically significant, particularly in the comparison of R1 to both the R2 and R3 banks. In other words, when also focusing on the most standard profitability measure (ROA), especially the R1 banks have benefitted from the introduction of negative money market interest rates at the onset.

The most important aspect of the economic narrative behind our analyses relies considerably on the hypothesis that the introduction of negative money market interest rates has induced a change in banks' business models, i.e., shifted the emphasis in their sources of funding further towards wholesale-based rather than traditional retail (deposit)based funding. This is because the individual banks within the OP Group have been able to enjoy the benefits from the negative overall (European) money market interest rates because the central cooperative has been willing to almost completely pass the negative interest rates through its central bank loan rates to the Group's individual member banks. Hence, it is clearly important to also investigate the dynamic dependence between the average values of WSF and EONIA mid-rate in the different bank size groups. From Fig. 4e, it is again clear that the introduction of negative rates in 2014/11 has also more or less permanently changed the dynamic conditional covariance structure between these variables. The obvious main interpretation of Fig. 4e's covariance series is that after the quotation of negative money market interest rates, the degree of WSF has increased as the interest rates have dropped deeper into the negative zone, which strongly supports our main hypothesis about the effects of negative interest rates on bank business models. In banks of all sizes, in average terms, the dependence on WSF has increased when the money market interest rates have become more negative. Additionally, when comparing the results shown in Fig. 4e (WSF against EONIA) with those in Fig. 4b (ROEC against EONIA), it is also clear that these two dynamic covariance series resemble one another remarkably closely in all bank size groups, except for the scale of covariances. Hence, the banks also continued to increase WSF during 2018, when the money market interest rates remained fairly deep, but stable (EONIA mid-rate exactly at -0.36 almost throughout the year), in the negative zone.

At the final stage of our analysis, we performed the asymmetric DCC- 
GARCH modelling for the dependence of the various profitability measures on the bank business model variable, i.e., the WSF ratio. These results also strongly support our earlier findings regarding the prominent effects of negative interest rates on the change in the business model and, hence, bank profitability. From Figs. 5a-5d, it is clear, that the improving profitability effect of increasing the ratio of wholesale funding might not have come through simply the effects on NIM, because the covariance between NIM and WSF has also been quite close to zero in the negative interest rate era (Fig. 5a). The covariance has become steadily more negative in recent years so, as the WSF has increased, the NIM has decreased or remained more or less the same. This is in connection with the fact that, as we already learned from Figs. 1a-1c, the NIM has almost not varied at all since the beginning of 2016 (because the market rates have not varied), so its mild (and even negative) reaction to the WSF may actually be quite reasonable. This interpretation is also valid for the years 2010-2011 during which, after the money market interest rates had suddenly dropped in mid-2009 but remained stable for about a year after that, the increases in WSF ratio were actually negative in relation to NIM.

When we extend our analyses from NIM to wider profitability measures, we find strikingly different results, supporting our earlier implications. First, the risk-adjusted, ROEC profitability of the largest banks appears to have been positively connected to the increases in WSF. This connection has begun to be valid exactly at the time of the launch of negative money market interest rates. ${ }^{27}$ For the smaller banks, the results are not so robust, although the dynamic conditional covariance relationship between WSF and ROEC is also positive throughout almost the entire sample. However, since 2017, this dependence has weakened and has almost vanished at the end of the sample period for the smaller banks, but for the R1 banks, it has remained strong until the end of the entire sample period.

The results for the non-risk-adjusted, more standard profitability measures again differ somewhat. Using the ROE as the profitability measure, when the WSF ratio has increased, the profitability has decreased especially for the R1 banks after the introduction of negative interest rates. Hence, when focusing on this measure, neither the largest nor the smaller banks have benefitted from increasing the WSF ratio during the negative interest rates period. Nevertheless, this conclusion seems once again to be highly sensitive to the selected profitability measure. If we focus on the most standard profitability measure used in previous studies, i.e. ROA, we see once again that throughout most of the negative money market interest rates era, the largest (R1) banks have been able to improve their ROA profitability by increasing the WSF ratio up until the beginning of Cappiello et al., 2006, after which the conditional covariance has started to decrease also for the R1 banks and in the most recent observations, the relationship between ROA and WSF appears to have become negative for the largest banks. In other words, increasing the WSF ratio no longer seems to improve the ROA so, in the most recent observations, both the ROE and ROA measures indicate similar conclusions with respect to the negative profitability effects of increases in the WSF ratio.

Our main findings until now, based on the analysis of dynamic connections between the various profitability measures with respect to the negative interest rates and to the role of banks' business models in the form of WSF ratio, are as follows. The standard textbook view that as the market interest rates increase (decrease) the NIM increases (decreases), is also valid for our data set, irrespective of the bank size

\footnotetext{
27 Around 2010-2011, after the significant drop in money market interest rates in mid-2009, the increasing WSF ratio has been positively connected in particular to the risk-adjusted profitability of R1 banks, but this relationship also began to weaken from 2012 onwards, when the level of money market interest rates began to stabilize. However, since the end of 2014, the positive relationship has strengthened throughout the rest of the sample for R1 but not for the smaller banks.
}

category. However, for all other profitability measures, we obtained somewhat varying and completely new results between the banks of different sizes. Our results reveal that it is essential to use several indicators for bank profitability, and among the most important ones is some kind of risk-adjusted measure of profitability. When using the OP Group specific risk-adjusted measure of Return on Economic Capital (ROEC), we find that, first, the introduction of negative money market interest rates has particularly improved the risk-adjusted profitability of the largest R1 banks on average. However, according to the most recent data this relationship has changed, because the slope of the dynamic conditional covariance between EONIA and ROEC has changed from negative to positive (although the actual covariance remains clearly negative) since the beginning of 2018. Furthermore, this improving profitability effect of negative rates at the start of their quotation is much more difficult to reveal if we use more traditional measures like ROE and ROA. Again, an exception here is the category of biggest banks, where also the ROA profitability seems to have improved since the beginning of the negative interest rate era due to the utilization of more WSF with a negative interest rate on central cooperative loans. However, none of these clear, new bank profitability implications of the era of negative interest rates would have been possible to reveal had the asymmetries in the variances of the analysed time series and their effects on the dynamic correlations (covariances) not been accounted for.

Because some of the most recent previous studies focusing on the period of negative nominal interest rates (especially Lopez et al., 2020, and Xu et al., 2019) specifically stress the role of other than the net interest margin income items in having effects on the bank profitability during this era, in the final part of our empirical analyses we applied the asymmetric DCC-GARCH modelling approach to analyse this point of view, too. Here we discuss these results only for the analysis regarding the role of other income items in having effects on the dynamic development of the risk-adjusted (ROEC) profitability, and on the other hand, for the connections between the business model measure (WSF) and the share of other income components in relation to bank assets. ${ }^{28}$

Figs. 5e and $5 \mathrm{f}$ support strongly our previous results and justify again the need for doing dynamic analysis in these data. The conditional covariance of the other income component with respect to the ROEC started to increase and was fairly unanimous between the different bank size categories from the quotation of negative interest rates up until the beginning of 2017, but after that, the covariance started a deep dive into the negative values especially in the data for the biggest R1 banks. Hence, especially in the biggest OP banks a prominently positive development of other income items based on strong extension of the balance sheet has not affected positively the risk-adjusted profitability of the banks in the most recent data anymore. A similar implication can be obtained also from Fig. $5 \mathrm{f}$ that shows a clear positive trend in the conditional covariance between the wholesale funding ratio and returns from other income components at the onset of the quotation of negative interest rates, between late 2014 and 2016. However, from the beginning of 2017 this trend has been strongly negative. Hence, in the most recent observations of the OP group data the increasing rate of wholesale funding ratio is not enabling profitability improvement stemming from further returns from other income items, but more likely, the effect on ROEC is negative. Hence, analogously to some of the recent studies mentioned above, we also find that in the longer run, the negative era of nominal money market interest rates is not beneficial for the (riskadjusted) bank profitability, because the development of all the main income items (both the net interest margin and other than income components) seem to be suffering from it.

\footnotetext{
${ }^{28}$ Results for the analysis of all the other profitability measures' covariance with the other income component. and for the covariance between EONIA and other income component are available upon request.
} 


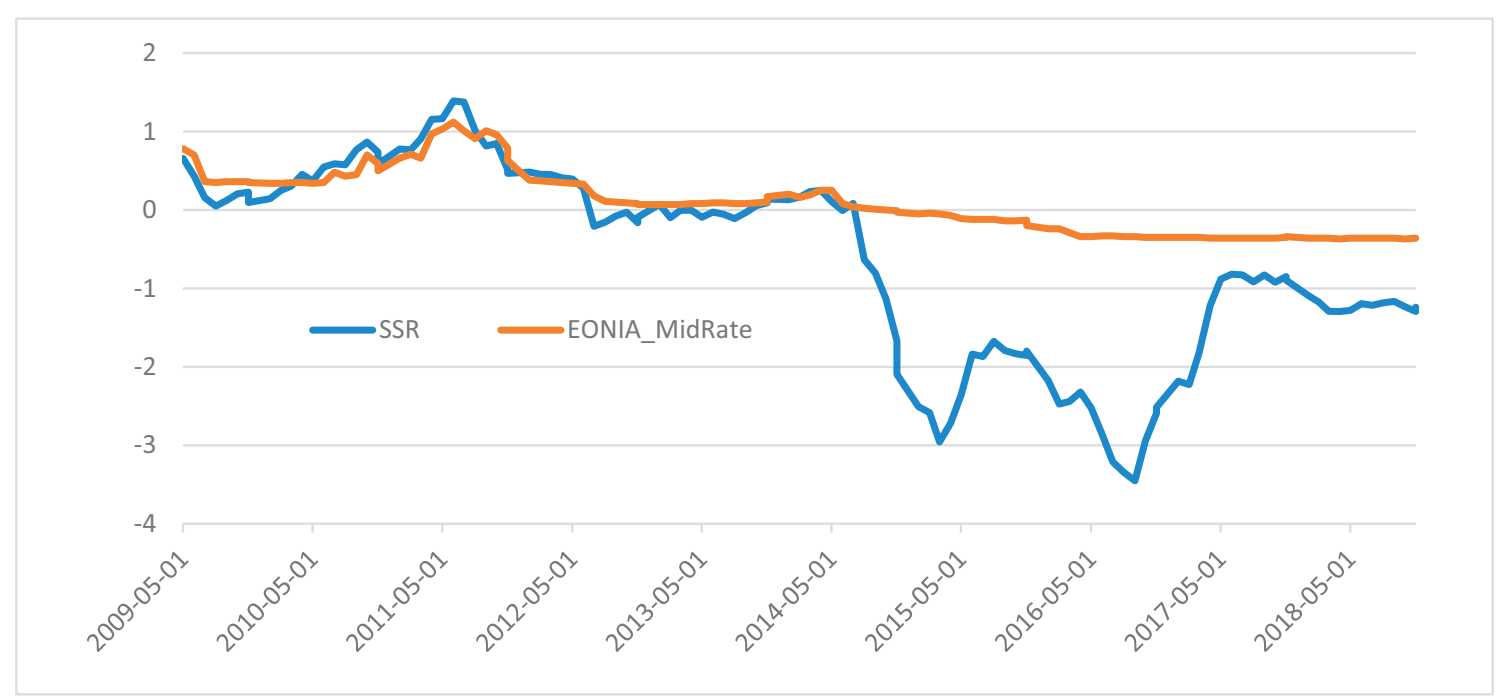

Fig. 6. Development of EONIA Midrate and the ECB shadow interest rate (SSR) (both in \%) during the sample period from 1/2009 to 12/2018. The data on shadow interest rate obtained from Tomi Kortela at the OP Group.

\subsection{Robustness check: The role of quantitative easing period}

Our empirical analyses have so far utilized the EONIA Midrate as the main money market interest rate to characterize also the changes in the main reference rates for example in customer loan pricing activities of the banks. Even though in view of the standard ideas in the term structure theories of interest rates, it is a relevant indicator, since it was the first that dipped into the negative era in the euro area money markets, and the Euribor interest rates with increasing maturities followed the path within couple of months in 2014-2015, other relevant interest rate information might be nowadays obtained from the so-called shadow interest rate observations. Put it simply, the shadow interest rate can be viewed as an implicit, factor-analysis based indicator of the efficient monetary policy steering rate that is not bounded by the zero lower bound, so it can also go deep in the negative territory in practise. ${ }^{29}$

We will use the shadow interest rate data based on Kortela (2016), updated to the observations covering our whole sample period until the end of 2018, to proxy the role of unconventional monetary policy actions in the form of quantitative easing $(\mathrm{QE})$ in the euro area. First of all, we acknowledge that the shadow rate data used here to help us to define the periods or the 'deepness' of QE are in fact capturing a large set of conditioning information (on macro variables and term structure of interest rate factor components), and hence, its usage as a direct indicator of 'effective' money market reference rate in every-day bank business activities is perhaps a bit questionable. However, since we also are well aware of its potential as a general measure for the efficient short-term implicit monetary policy steering rate, and as can be seen from Fig. 6, it is much more time-varying than e.g. the official central bank steering rates (like the deposit facility rate, DFR), we use it in our analysis based on the following idea.

First, when remembering that the ROE profitability was found to be strongly correlated with some other measures, like the NIM and ROA, we will use it as a measure of non-risk-adjusted profitability. Furthermore,

\footnotetext{
${ }^{29}$ A set of research papers introducing the main ideas in the calculation of shadow interest rates includes Krippner (2015), Wu and Xia (2016), Christensen and Rudebusch (2016), and Bauer and Rudebusch (2016) for the US data. For euro area, the papers like Lemke and Vladu (2014), Pericoli and Taboga (2015), and for the UK, Andreasen and Meldrum (2015) have also analysed shadow interest rates. Our empirical analysis is based on the shadow interest rate data obtained directly from Tomi Kortela at the OP Group, where the original reference is Kortela (2016). The very first shadow rate models were presented by Black (1995) and Bomfim (2003).
}

because the dependence of risk-adjusted profitability, ROEC, on the market development, and also on the wholesale funding ratio, was clearly the one with biggest differences between the banks of different size categories, we will focus on that, too. Hence, the dependent variable in our final robustness checks for the role of QE effects is the difference between the risk-adjusted and non-risk-adjusted profitability, and we define it as to be representing the risk premium of bank profitability. The main argument for this is that as seen from the definitions for the analysed profitability measures given in section 3 and Appendix B, the return on economic capital (ROEC) adjusts for the riskiness of activities only by adjusting the required amount of economic capital assumed to be covering for the expected losses in extreme conditions. However, it is obvious that in this kind of risk adjustment, it is not actually the numerator (return or profits) of the profitability measure that is being adjusted, but only the denominator, the capital. Hence, when we analyse the difference between ROEC and ROE (in levels), ${ }^{30}$ we are giving now also a prominent role for the required risk premium, based on a set of relevant conditioning information that might be affecting on it, i.e., the difference between the risk-adjusted and non-risk-adjusted returns.

Since in our previous analyses the relevant horizon for the dynamic dependencies between the analysed variables was revealed to be one month, we are essentially using here now a forecasting equation for the risk premium (RP), i.e., the difference between ROEC and ROE. The conditioning information set in this forecasting exercise comes, first of all, from the lagged value of risk premium and the EONIA Midrate, as it was found to be relevant for all the profitability measures. However, to control for the QE effects at the first stage, we also add now the past difference between the shadow interest rate and EONIA Midrate (denoted QE), as the variable that indicates the effects of unconventional monetary policy actions on the difference between the risk-adjusted and non-risk-adjusted profitability. We also have to take into account that in all our earlier regression analyses there was a possibility for unit roots in the data generating processes of the variables, and especially the months around the break point related to the start of negative nominal rate era seemed to be relevant in this. Hence, we do the regression analyses once again for the whole sample, but also for the two subsamples, where the break point was in October 2014, when the EONIA midrate went negative permanently.

\footnotetext{
${ }^{30}$ We are very grateful to an anonymous referee for suggesting us to take a closer look at the prominent importance of the relationship between ROEC and $\mathrm{ROE}$, and also to discuss the role of shadow interest rates in our analyses.
} 
Table 5

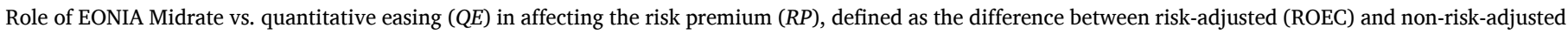
profitability (ROE).

\begin{tabular}{|c|c|c|c|c|c|c|c|c|c|c|c|c|}
\hline \multirow[b]{2}{*}{$\begin{array}{l}\text { Dependent/ } \\
\text { Independent variables }\end{array}$} & \multirow[b]{2}{*}{$R P_{t}$} & \multirow[b]{2}{*}{$R P_{t}$} & \multirow[b]{2}{*}{$R P_{t}$} & \multicolumn{3}{|c|}{ Whole sample } & \multicolumn{3}{|c|}{ Sub-sample 2009:1-2014:10 } & \multicolumn{3}{|c|}{ Sub-sample 2014:11-2018:12 } \\
\hline & & & & $R P_{t}$ & $d R P_{t}$ & $d R P_{t}$ & $R P_{t}$ & $d R P_{t}$ & $d R P_{t}$ & $R P_{t}$ & $d R P_{t}$ & $d R P_{t}$ \\
\hline \multicolumn{13}{|l|}{ R1 Banks } \\
\hline Constant & $0.59^{* * *}$ & 0.28 & 0.47 & $0.61^{* * *}$ & 0.11 & - & 0.66 & 0.04 & - & $3.18^{* *}$ & 0.17 & - \\
\hline$R P_{t-1}$ & $0.96^{* * *}$ & $0.99^{* * *}$ & $0.97^{* * *}$ & $0.96^{* * *}$ & - & - & $0.94^{* * *}$ & - & - & $0.87^{* *}$ & - & - \\
\hline$E O N I A_{t-1}$ & $-0.47^{* *}$ & - & - & - & - & - & $-0.42 * *$ & - & - & -0.87 & - & - \\
\hline$Q E_{t-1}$ & $-0.38^{* * *}$ & - & - & - & - & - & -0.30 & - & - & -0.06 & - & - \\
\hline$d R P_{t-1}$ & - & - & - & - & $0.16^{* *}$ & $0.18^{* *}$ & - & -0.02 & -0.02 & - & $0.26^{* * *}$ & $0.30 * * *$ \\
\hline$d Q E_{t-1}$ & - & - & - & - & -0.53 & -0.53 & - & -0.32 & -0.32 & - & -0.69 & -0.68 \\
\hline EONIAPlus $_{t-1}$ & - & $-0.57 * * *$ & $-0.46^{* * *}$ & $-0.49 * *$ & - & - & - & - & - & - & - & - \\
\hline EONIAMinus $_{t-1}$ & - & -1.29 & -0.91 & - & - & - & - & - & - & - & - & - \\
\hline QEMinus $_{t-1}$ & - & - & $-0.36^{* *}$ & $-0.36^{* * *}$ & - & - & - & - & - & - & - & - \\
\hline$D W$ & 1.80 & 1.76 & 1.84 & 1.80 & 2.08 & 2.08 & 2.00 & 2.02 & 2.012 & 1.65 & 2.08 & 2.11 \\
\hline$R^{2}$ & 0.99 & 0.99 & 0.99 & 0.99 & 0.03 & 0.02 & 0.88 & 0.03 & 0.00 & 0.94 & 0.06 & 0.05 \\
\hline \multicolumn{13}{|l|}{ R2 Banks } \\
\hline Constant & $1.44^{* * *}$ & $0.88^{*}$ & $1.38^{* * *}$ & $1.39 * * *$ & 0.04 & - & $1.77^{* * *}$ & -0.00 & - & 3.43 & 0.13 & - \\
\hline$R P_{t-1}$ & $0.92^{* * *}$ & $0.96^{* * *}$ & $0.92^{* * *}$ & $0.92^{* * *}$ & - & - & $0.89^{* * *}$ & - & - & $0.86^{* * *}$ & - & - \\
\hline$E^{\prime}{ }^{\prime} A_{t-1}$ & $-0.61^{* * *}$ & - & - & - & - & - & $-0.55^{* * *}$ & - & - & -0.20 & - & - \\
\hline$Q E_{t-1}$ & $-0.38^{* * *}$ & - & - & - & - & - & -0.60 & - & - & -0.20 & - & - \\
\hline$d R P_{t-1}$ & - & - & - & - & 0.08 & 0.08 & - & 0.13 & 0.13 & - & 0.05 & 0.06 \\
\hline$d Q E_{t-1}$ & - & - & - & - & $-0.83^{\star}$ & $-0.84^{*}$ & - & -0.44 & -0.44 & - & $-1.14 * *$ & $-1.14^{* *}$ \\
\hline EONIAPlus $_{t-1}$ & - & $-0.71^{* * *}$ & $-0.57^{* * *}$ & $-0.57 * * *$ & - & - & - & - & - & - & - & - \\
\hline EONIAMinus $_{t-1}$ & - & -0.19 & -0.03 & - & - & - & - & - & - & - & - & - \\
\hline QEMinus $_{t-1}$ & - & - & $-0.37^{* * *}$ & $-0.37^{* * *}$ & - & - & - & - & - & - & - & - \\
\hline$D W$ & 1.90 & 1.84 & 1.89 & 1.89 & 2.00 & 2.00 & 1.78 & 2.03 & 2.03 & 1.89 & 1.88 & 1.87 \\
\hline \multirow[t]{3}{*}{$R^{2}$} & 0.98 & 0.98 & 0.98 & 0.98 & 0.02 & 0.03 & 0.92 & 0.00 & 0.01 & 0.78 & 0.03 & 0.04 \\
\hline & & & \multicolumn{3}{|l|}{ Whole sample } & & \multicolumn{3}{|c|}{ Subsample 2009:1-2014:10 } & \multicolumn{3}{|c|}{ Sub-sample 2014:11-2018:12 } \\
\hline & $R P_{t}$ & $R P_{t}$ & $R P_{t}$ & $R P_{t}$ & $d R P_{t}$ & $\overline{d R P_{t}}$ & $R P_{t}$ & $d R P_{t}$ & $d R P_{t}$ & $R P_{t}$ & $d R P_{t}$ & $d R P_{t}$ \\
\hline \multicolumn{13}{|l|}{ R3 Banks } \\
\hline Constant & $1.65^{* * *}$ & $1.34^{* * *}$ & $1.55^{* * *}$ & $1.51 * * *$ & -0.00 & - & $1.88^{* * *}$ & -0.05 & - & 3.11 & 0.10 & - \\
\hline$R P_{t-1}$ & $0.90^{* * *}$ & $0.93^{* * *}$ & $0.91 * * *$ & $0.92^{* * *}$ & - & - & $0.88^{* * *}$ & - & - & $0.86^{* * *}$ & - & - \\
\hline$E^{\prime}{ }^{\prime} A_{t-1}$ & $-0.71 * * *$ & - & - & - & - & - & $-0.62^{* *}$ & - & - & -0.07 & - & - \\
\hline$Q E_{t-1}$ & $-0.33^{* *}$ & - & - & - & - & - & -0.44 & - & - & -0.15 & - & - \\
\hline$d R P_{t-1}$ & - & - & - & - & $0.18^{* *}$ & $0.18^{* *}$ & - & $0.26^{* *}$ & $0.26^{* *}$ & - & 0.12 & 0.12 \\
\hline$d Q E_{t-1}$ & - & - & - & - & -0.69 & -0.69 & - & -0.22 & -0.21 & - & $-1.00 * *$ & $-1.00 *$ \\
\hline EONIAPlus $_{t-1}$ & - & $-0.89 * * *$ & $-0.70^{* * *}$ & $-0.71^{* * *}$ & - & - & - & - & - & - & - & - \\
\hline EONIAMinus $_{t-1}$ & - & $-0.77^{* * *}$ & -0.19 & - & - & - & - & - & - & - & - & - \\
\hline QEMinus $_{t-1}$ & & - & $-0.31^{* * *}$ & $-0.32^{* * *}$ & - & - & - & - & - & - & - & - \\
\hline$D W$ & 1.78 & 1.74 & 1.79 & 1.78 & 2.02 & 2.02 & 1.77 & 2.03 & 2.04 & 1.74 & 1.95 & 1.95 \\
\hline$R^{2}$ & 0.97 & 0.97 & 0.97 & 0.97 & 0.04 & 0.05 & 0.94 & 0.05 & 0.06 & 0.77 & 0.04 & 0.04 \\
\hline
\end{tabular}

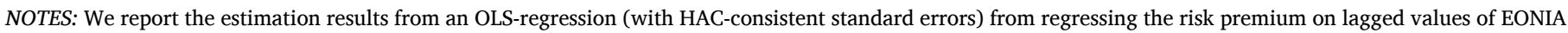

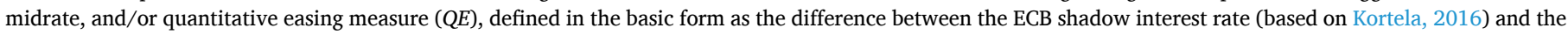

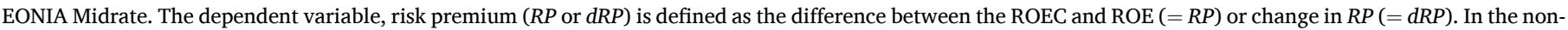

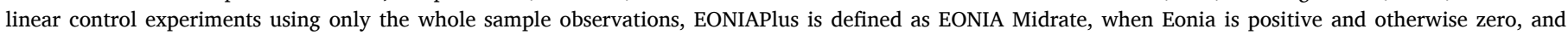

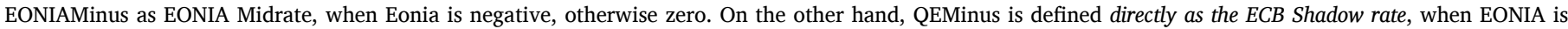

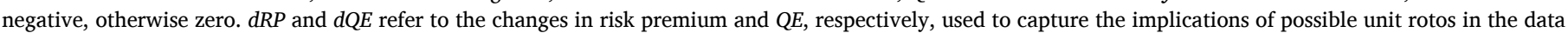

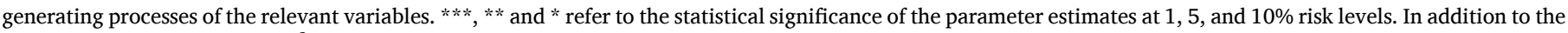
coefficient of determination $\left(R^{2}\right)$ values, we report the Durbin-Watson (DW) test values as the goodness of fit statistics.

For the part of differenced values of the variables (RP and QE) we do the analysis for subsamples, ${ }^{31}$ too, but especially in the whole sample data we wanted to put even more emphasis to the periods when the EONIA Midrate obtained negative values. Hence, we control also for these switching, i.e., nonlinear effects by setting up indicator (dummy) variables to reflect the periods, when the EONIA Midrate was either in the positive or negative era, and whether the effect of shadow interest rate on the risk premium is different when the EONIA Midrate is negative, too. Hence, in the last experiment for the whole sample levels observations, we define the QE measure to be directly given by the shadow

\footnotetext{
${ }^{31}$ Using the differenced values for RP and QE did not reveal statistically significant new results compared to the whole sample results for the levels of variables, so we will not discuss those in further details, even though they are also reported in Table 5.
}

interest rate (denoted as QEMinus), when the EONIA Midrate is below zero.

The results in Table 5 reveal once again the essential role of the negative values of the EONIA Midrate. In the whole sample results we see that there seems to be a statistically significant drift term in the risk premium series for all the bank size categories. Furthermore, since the constant term in the regressions reflects this average value of the risk premium and it increases when the bank size group gets smaller, the smallest, R2 and R3 banks have the highest risk premia, and they are always more than double the average premium for the R1 banks. Even more interestingly, the average risk premium is not even statistically different from zero for the biggest (R1) banks, when we control separately for the effects of positive EONIA midrate observations and use the shadow interest rate as the reference rate, when EONIA midrate goes below zero (see column 3 results in Table 5). However, the average risk premium is still very high for both the R2 and R3 banks in this case, too. 
Furthermore, irrespective of whether we define the QE variable as the difference between the shadow rate and EONIA, or directly as the shadow rate, when EONIA is negative, the QE effect is quite similar in all banks. In other words, when the QE efforts accelerate, i.e., when the shadow rate goes deeper in the negative zone, it has a lowering effect on the risk premium, and the scale of this effect is around 31-38 basis points in all banks, so this really is a large effect. Put it in other words, in terms of lowering the overall riskiness of banking activities, our results speak in favour of using the QE, but it is worth to note that the effects on bank profitability directly, and especially over time, cannot be observed from these results, because they are based on the whole sample parameter estimates, and hence, e.g. the time-variation in the dependencies between the variables is not captured here parametrically. This will be done based on DCC-GARCH analyses.

Finally, we can also see from the results reported in the first four columns of Table 5 that for the smallest (R3) banks both the negative and positive values of EONIA have a lowering effect on the risk premium, whereas for the bigger (R2 and R1) banks only the positive values of EONIA lower the risk premium, and also this effect is milder. These additional results for the effects of negative interest rate era once again emphasize the clear differences between the three size categories of Finnish OP Group banks. Hence, from the policy recommendations point of view, also these results actually imply that the biggest (R1) banks are probably very different in terms of their scales and diversity of customer business activities, because also their risk premium development and its dependence on the market situation and reference rates is different from the smaller banks. These implications are also clear when we look at the time-varying development of DCC covariances of the various profitability measures against the shadow interest rate, reported in an online Appendix AI. These results confirm that the introduction of negative money market interest rates, and the accompanying deep dive of shadow interest rate around 2014-2016, when the negate money market interest rates stayed fairly constant, has a very different effect on R1 banks compared to the other two size reference groups. A general message from e.g. Fig. A1 is that when the shadow rate went very deep into the negative side around 2015-2016, the risk adjusted profitability of especially the R1 banks improved at the same time. However, also from the DCC covariance figures based on the shadow rate we see the previously observed similar implications for the last two years in our data, that the negative conditional covariance has started to diminish and has moved towards even positive dependence. This once again raises serious concerns for the future profitability of all banks when the negative interest rate period seems to be lasting clearly longer than was perhaps originally planned by the central bank policy makers.

\section{Conclusions}

Based on careful application of a set of various time-series analytical tools, we obtain somewhat revolutionary results regarding the average profitability of the Finnish OP banks in the three size reference categories during the period of negative interest rates. One of our study's main innovations was to use a risk-adjusted profitability measure, and it appears to result in completely new implications. One clear result is that the largest (R1) banks have been able to reap the greatest advantages from the period of negative money market interest rates during the first couple of years of the quotation of negative money market interest rates. This is based on the fact, that although all the individual OP banks have had the chance to shift their business models towards more wholesale funding profitably based on the negative central cooperative loan interest rates, the largest banks seem to have had the greatest interest in doing so. However, in the face of the long period of prevailing negative rates after the Corona crisis, we also find very alarming results based on the most recent OP data, because it seems that from the beginning of 2017 the advantageous connection between (risk-adjusted) profitability and more negative interest rates, along with increasing rate of wholesale funding has started to vanish. In other words, even though banks still get their funding with negative interest rate from the central co-operative, they have not been able to improve their profitability anymore based on that. More specifically, even though the standard ROA- and ROEbased profitability measures are also in the most recent data improving in connection to the other than interest income items, especially the risk-adjusted (ROEC) profitability has been decreasing along with the rising return from other income items. This alarming development has been especially strong in the biggest banks during the last two years of our data.

As noted above in our literature review, the number of studies on bank profitability utilizing actual negative (nominal) interest rate data remains limited. However, the results of some earlier studies resemble ours at least partially. For example, Turk-Ariss (2016) found from the data on Swedish and Danish banks that reductions in WSF costs based on the negative interest rates have offset the lower interest income and that bank profitability has not suffered from negative interest rates in Sweden and Denmark too much. In fact, our Finnish cooperative bank data indicate that profitability has improved as a result of the utilization of central cooperative loans with negative interest rates during the first 2-3 years of negative market rates, but not in the most recent data, particularly in the largest R1 banks. Furthermore, for example Eggertsson et al. (2019) found that at extremely low (and negative) interest rate levels, banks might actually have been able to increase their lending margins, and this has improved bank profitability. However, our results imply that also this might not be valid in the most recent data on Finnish OP banks, at least when we consider their risk-adjusted profitability measures.

Our results are in favour of some earlier studies that have actually advocated the possibility that over-reliance on WSF during the negative interest rate era might increase the systemic risk to the banking sector. We also strongly question the profitability of too long over-reliance on WSF, even with negative nominal reference rates. Since the OP Group currently holds almost a $40 \%$ share of most banking business segments (e.g. housing loans) in Finland, this is a significant concern in the Finnish context. Nevertheless, due to the relatively small proportional role of the entire OP Group in the European banking markets, this may not induce further systemic risk stemming solely from Finland's OP banks. However, if similar time-varying behaviour with respect to the reaction of profitability to market interest rates were to be revealed from the data on the largest European banks, this may also clearly raise some serious systemic risk concerns. Compared to previous studies, from a somewhat different perspective, our results indicate these same concerns, because the largest banks appear to have increased the volume of customer lending based on WSF to the greatest extent. The alarming aspect of this development can be most clearly seen from the time-series behaviour of the various dynamic conditional covariances between the profitability measures and EONIA or WSF ratio, because the volatility and the range between minimum and maximum values of the dynamic covariances is also the greatest for the data on R1 banks across all our analyses. Hence, when the money market reference rates and, as a follow-up, the WSF ratio change, particularly in the negative interest rate zone, the effects are the strongest for the biggest (R1) OP banks, which constitute the major part of all customer activity volumes in all business areas of the OP Group.

Another very relevant finding from our results is that even though it seems to be the case that the unconventional monetary policy actions (QE) have had a lowering effect on the risk premium, defined here as the difference between the risk-adjusted (ROEC) and non-risk-adjusted (ROE) profitability, the last two years of data also witness a decreasing effect on overall profitability of banks as the market interest rates and also the shadow interest rate have remained in the negative era, and even still lowered from time to time. For example, the biggest banks' non-risk-adjusted return on assets (ROA) profitability has also started to lower along with the lowering of nominal reference rates (because the conditional DCC covariance has turned positive, see Fig. AI.3 in Appendix AI), so the overall profitability development of the 
whole OP group might be in danger if the negative interest rate era continues far into the future, and starts to be the new norm.

Our results obviously require in the future a much more detailed, panel data methodological analysis, and furthermore, also utilization of more recent observations, and of also an international data set, where the role of ownership structures and many other relevant variables affecting the bank profitability are controlled much more carefully. However, our current findings already serve as a good starting point, and we have uncovered some interesting, completely new findings already from this Finnish OP Group data set and observations based on the average values of the data within the size reference categories of the analysed banks.

\section{Appendix A}

Structure and selected details of the OP Financial Group (as of December 2018)

(see also https://www.op.fi/op-financial-group/about-us/corporate-governance/group-structure and the 2018 financial statement and annual report, from which the selected details are extracted exactly as reported in the statement and report)

OP Financial Group was established in 1902 as a cooperative financial services group formed by independent cooperative banks and the Group's central cooperative with its subsidiaries operating under the principle of joint and several liability. At the end of 2018, OP Financial Group consisted of 156 member cooperative banks and their central cooperative, OP Cooperative, with its subsidiaries and affiliates. The Group's operations are based on the cooperative principle, which aims to create sustainable prosperity, security, and well-being for its owner-customers and in its operating region by means of its strong capital base and efficiency.

OP Financial Group's business was divided into three segments that were valid until the end of 2018: banking, non-life insurance, and wealth management. However, a new business segments structure took effect on 1st January 2019. These new business segments are banking for private and SME customers, banking for corporate and institutional customers, and banking for insurance customers. OP Financial Group consists of the following amalgamation of OP Financial Group cooperative banks and other entities and organizations of OP Financial Group.

The amalgamation is formed by OP Cooperative (the central cooperative), companies belonging to its consolidation group, the central cooperative's member credit institutions and companies belonging to their consolidation groups, and credit institutions, financial institutions and service companies, in which the abovementioned institutions jointly hold more than half of the voting rights. OP Financial Group is comprised of the amalgamation and those non-amalgamation entities of which entities belonging to the amalgamation hold more than half of the total votes. The extent of OP Financial Group differs from that of the amalgamation, in that OP Financial Group subsumes companies other than credit and financial institutions or service companies. The most important of these are the insurance companies with which the amalgamation forms a financial and insurance conglomerate. Additionally, Pohjola Health Ltd., a hospital, belongs to OP Financial Group.

OP cooperative banks are independent, local deposit banks engaged in retail banking. They provide modern and competitive banking services to households, SMEs, agricultural and forestry customers, and public-sector entities. Helsinki Area Cooperative Bank, which belongs to the central cooperative consolidated and whose governance model and structure differs from that of other OP cooperative banks, engages in corresponding retail banking in the Helsinki Metropolitan Area. In terms of the type of their business organization, the member cooperative banks are cooperatives whose basic values underlying their decision-making include the one member, one vote principle. Within the OP cooperative banks, the owner-customers' decision-making power is exercised by the Representative Assembly, comprising owner-customers, or the cooperative meeting, which elects a supervisory board for the bank. The Supervisory Board in turn elects a board of directors for the bank.

The central cooperative of OP Financial Group is OP Cooperative in English and OP Andelslag in Swedish and is domiciled in Helsinki. Within the central cooperative, the decision-making powers of member cooperative banks rest with the Cooperative Meeting and the Supervisory Board elected by it, and operational decision-making powers are exercised by the Executive Board acting as the board of directors, elected by the Supervisory Board and composed of management executives. The central cooperative's member banks own OP Cooperative. The central cooperative's members may include credit institutions, as referred to in the Act on the Amalgamation of Deposit Banks, whose Bylaws or Articles of Association have been approved by the central cooperative. The Supervisory Board takes decisions on admitting new members.

Based on the financial statements of the OP Financial Group at the end of $2018,{ }^{32}$ the OP Financial Group-level earnings before tax amounted to EUR 1017 million (1031 in 2017). Income from customer business activities improved, because net interest income increased by $7 \%$ to EUR 1175 million and net commissions and fees by $1 \%$ to EUR 887 million. Net insurance income increased by $19 \%$ to EUR 566 million - comparable change was $-2 \%$. Investment income fell by $46 \%$ to EUR 280 million and other operating income by $26 \%$ to EUR 61 million. Investment income was affected by a year-on-year decrease of EUR 227 million in capital gains. Expenses decreased by 5\% to EUR 1681 million.

Concentrating particularly on the profitability and scale of the banking business, earnings before tax amounted to EUR 795 million (619). Total income increased by $4.8 \%$, and net interest income increased by $4.2 \%$ year on year, but net commissions and fees decreased by $6.3 \%$. Total expenses decreased by $9.5 \%$ to EUR 878 million. The transfer of the earnings-related pension liability decreased personnel costs by EUR 172 million. Other operating expenses increased by $18.1 \%$ due to the stability contribution, development costs and higher volumes.

In actual banking business, the loan portfolio increased by $5.9 \%$ to EUR 87.1 billion and the deposit portfolio by $5.8 \%$ to EUR 61 billion. Hence, a significant aspect of the loan portfolio at the entire group level is funding based on the acquisition of wholesale funding from the interbank markets. The loan portfolio showed the fastest growth in corporate loans as well as housing company loans and other loans. Impairment losses amounted to EUR 45 million (47). Non-performing receivables accounted for 1.0\% (1.2) of the loan and guarantee portfolio. The most significant banking development investments involved the upgrades of payment and finance systems, for example, those concerning the development of the digital home loan service. OP Financial Group's banking comprises banking for private and SME corporate customers as well as that for corporate and institutional customers. OP cooperative banks are mainly responsible for banking for private and SME corporate customers. The corporate and institutional customer business is almost entirely centralized in OP Corporate Bank, which accounts for $26 \%$ of the loan portfolio and $19 \%$ of the deposit portfolio.

Home loan borrowers have historically enjoyed low interest rates for an exceptionally long time, and customers have demonstrated greater interest

\footnotetext{
32 For more details, see https://www.op.fi/documents/209474/31336404/OP+Financial +Group +Report +by + the +Executive +Board +and +Financial + Statements +2018/47db0917-a4c0-8768-9d41-796039598ca0
} 
in protecting their home loans and housing company loans against higher interest rates. At the end of the financial year, 19.7\% (11.5) of private customer home loans were covered by the interest rate protection. The number of banking customers totalled 3.6 million (3.7) at the end of December 2018.

\section{Appendix B}

Components in the calculation of the Return on Economic Capital (ROEC)

(original source: OP Group Intranet, permission to publish obtained from the Group Control by Esa Vilhonen)

Partly due to the requirements induced by the Basel Accords (I to III, and the forthcoming IV), the calculation procedure for ROEC in the OP Group has evolved throughout the years since its adoption around 2007-2008. In the most recent version, the bank-specific final income after taxes, balance sheet items and economic capital (EC) requirement are divided into two parts: the first is connected to the customer business activities and the other to ownership. The exact term for the new profitability measure is the 'return on economic capital based on customer business activities' (ROECCBA) but, in our study we will use the shorter acronym, i.e. the 'return on economic capital' (ROEC). In the most recent version of ROECCBA calculation (= ROEC in our study), the values are based on.

$R O E C=\frac{(\text { Operating income }+ \text { customer bonuses }) \times(1-\text { tax rate })}{\text { Economic Capital Requirement on Customer Business Activities (cum.) }} \times 100 \%$.

More specifically, the role of individual items in the ROEC calculation is roughly based on the following decompositions:

\section{Decomposition of income into its components}

The financial result (operating income) is divided into income statement items as:

Customer business activity (income items $(+)$ and expenses $(-)$ )

+ Net Interest Margin (NIM) excluding the NIM from ownership

+ Net income from fees and commissions

- Expenses

- Impairment of assets

- Bonuses

$=$ Operating income

\section{Ownership}

+ Part of NIM

+ Returns from income based on own capital (equity) and items alike

+ Net income from trading in asset markets and currency market activities

+ Sales profits from financial assets available for sale

+ Net returns from investments in real estate

+ Impairment of other financial assets

= Operating income

\section{Decomposition of balance sheet and net interest income}

To decompose the NIM into customer business activities and ownership, the balance sheet is also decomposed into two corresponding parts. In practice, this is based on extracting the ownership items from the bank balance sheet, and the remaining part constitutes the share of balance sheet items connected to the customer business activities. The decomposition of balance sheet is based on the following principles:

- Equity, fund, and bond market investments are allocated to ownership.

- Structured investments are allocated to customer business activities.

- Own capital (equity) is decomposed so that part of it is allocated to customer business activities with a constant multiplier of 3 (i.e. $3 \times$ the EC requirement amount of customer business activities) and the rest is allocated to ownership.

- After these allocations, the new balance sheets are levelled with a levels item, for which an interest expense (if the levels item is in liabilities) or an interest return (if the levels item is in assets) is calculated using the 12-month Euribor rate.

\section{Investments allocated to the balance sheet based on ownership}

+ Debt securities

+ Other domestic bonds

+ Equity and shares

+ Real estate investments

\section{Amount of own capital (equity) due to ownership}

+ Own capital (equity)

+ Appropriations after tax deductions based on $20 \%$ tax liability

$-3 \times$ the EC requirement amount of customer business activities 


\section{Interest income items due to NIM from ownership}

Interest returns from investments on ownership are allocated to NIM based on:

+ Interest returns from debt securities

+ Interest returns from other domestic bonds

\section{Decomposition of the requirement for economic capital (EC)}

The EC requirement is decomposed between the customer business activities (CBA) and ownership, as follows:

- Items of EC requirement allocated completely to CBA:

- Interest rate risk

- Other measurable risks

- Items of EC requirement allocated completely to ownership:

- Equity risk

- The following ROEC items are allocated to ownership and CBA, as follows:

- Credit risk

- credit risk from debt securities is allocated to ownership, other credit risks to CBA

- Real estate risk

- investments in real estate are allocated to ownership

- the share of real estate in own use is allocated to CBA

- Operational risk

- allocated based on the relative shares of returns from the forms of operational activities

The share of ownership in the EC requirement on operational risk is calculated based on the value of previous year's income from ownership in relation to total income, as

Income from ownership /Total income $\times$ EC requirement for operational risk, where

Income from ownership $=$ Interest returns from ownership + net income from asset market trading + net income from financial assets available for sale + net income from investments in real estate

Total income $=$ Income from ownership + NIM from CBA + Net income from fees and commissions + Other income from business activities

\section{Appendix C}

The original, confidential individual bank-level database reports the return on assets (ROA) of each bank on a monthly basis. However, the monthly ROA values are calculated in terms of the ratio of cumulative earnings (from the beginning of the calendar year) to the corresponding average value of assets. Clearly, in this case, the ratio does not actually measure the month-specific profitability appropriately. Furthermore, the time-series observations of the ratio appear to be noisy and contain obvious outlier observations. As the database reports the monthly revenues and expenses item by item, we decided to recalculate for example the monthly earnings and the ROA values in the following way, to get a more appropriate measure for the monthly values of this standard profitability indicator

First, we detected the outlier observations in the interest revenues and interest expenses. An observation (in a few cases, a pair of adjacent observations) in a time series was identified as an outlier if it deviated (in terms of the percentage change) by more than two standard deviations from both the previous and the next observation in the time series. The standard deviation of the percentage changes was calculated separately for each bank and also separately for the interest revenues and expenses. The filtered value of the observation was adjusted to have a change of one standard deviation instead. The final time series of the net interest margin (NIM) is then calculated based on the adjusted values for the interest revenues and interest expenses.

The other revenue and expense items (13 variables altogether in the original data set) are treated using a similar kind of procedure. In these cases, the standard deviations of the time-series variables were also calculated separately for each bank, and an observation was identified as an outlier, if it was further than three standard deviations from both the previous and the next observations in the time series. Here, the value of the observation was adjusted according to the time-series mean of the variable. The variables also appeared to contain relatively strong seasonality (primarily due to accounting practices) so, for the purpose of smoothing the seasonal components from the monthly observations, we used 12-month moving averages of the time-series observations on all variables.

In the case of the variable 'revenues from equity investments', there were a few abnormal observations, which are common to (almost) all banks in the data. The observations typically represent revenues from block trades by the OP Financial Group. An example of these regular items is the return on ownership of the central cooperative, which is credited to the member banks in March every year. These observations were also cleaned from the data.

Finally, we re-calculated the monthly earnings using the adjusted variables, and calculated the adjusted monthly return on assets (ROA) and return on equity (ROE) observations, using the previous month Total Asset and Equity values as the denominators in the two ratios.

The time series for the risk-adjusted measure of profitability, i.e. the Return on Economic Capital (ROEC) do not seem to contain similar kinds of seasonal components as did the ROA and ROE values. Hence, we use the original raw data from each individual bank for ROEC, after cleaning some obvious outliers, probably due to data entry errors or sudden, abrupt (monthly level) changes in the calculation process, which can also be treated as recording errors.

\section{Appendix A. Supplementary data}

Supplementary data to this article can be found online at https://doi.org/10.1016/j.irfa.2021.101724. 


\section{References}

Agarwal, R., \& Kimball, M. S. (2019). Enabling deep negative rates to fight recessions: A guide. IMF working paper WP/19/84.

Alessandri, P., \& Nelson, B. D. (2015). Simple banking: Profitability and the yield curve. Journal of Money, Credit and Banking, 47(1), 143-175.

Altavilla, C., Burlon, L., Giannetti, M., \& Holton, S. (2019). Is there a Zero Lower Bound? The Effects of Negative Policy Rates on Banks and Firms. CEPR discussion paper 14050.

Andreasen, M., \& Meldrum, A. (2015). Market beliefs about UK monetary policy lift-off horizon: A no-arbitrage shadow rate term structure model approach, Discussion paper, Bank of England.

Angori, G., Aristei, D., \& Gallo, M. (2019). Determinants of banks' net interest margin: Evidence from the euro area during the crisis and post-crisis period. Sustainability, 11, 3785. https://doi.org/10.3390/su11143785, 2019.

Asongu, S. A., \& Odhiambo, N. M. (2019). Size, efficiency, market power, and economies of scale in the African banking sector. Financial Innovation, 5(4), 1-22.

Berger, A. N., \& Bouwman, C. H. S. (2013). How does capital affect bank performance during financial crises? Journal of Financial Economics, 109, 146-176.

Bikker, J. A., \& Vervliet, T. M. (2017). Bank profitability and risk-taking under low interest rates. International Journal of Finance \& Economics, 23, 3-18.

Black, F. (1995). Interest rates as options. The Journal of Finance, 50(5), 1371-1376.

Bomfim, A. (2003). Interest rates as options: Assessing the markets view of the liquidity trap. Discussion paper, Finance and Economics Discussion Series, Federal Reserve Board.

Bottero, M., Minoiu, C., Peydro, J.-L., Polo, A., Presbitero, A. F., \& Sette, E. (2019). Negative Monetary Policy Rates and Portfolio Rebalancing: Evidence from Credit Register Data. IMF working paper WP/19/44.

Cappiello, L., Engle, R. F., \& Sheppard, K. (2006). Asymmetric dynamics in the correlation of global equity and bond returns. Journal of Financial Econometrics, 4(4), 537-572.

Chaudron, R. F. D. D. (2018). Bank's interest rate risk and profitability in a prolonged environment of low interest rates. Journal of Banking and Finance, 89, 94-104.

Chen, Q., Katagiri, M., \& Surti, J. (2018). Banking in a steady state of low growth and interest rates. IMF working paper WP/18/192.

Christensen, J., \& Rudebusch, G. (2016). Modeling yields at the zero lower bound: are shadow rates the solution? In E. Hillebrand, \& S. Koopman (Eds.), vol. 35. Dynamic Factor Models (pp. 75-125).

Claessens, S., Coleman, N., Donnelly, M., \& M.. (2018). "Low-for-long" interest rates and banks' interest margins and profitability: Cross-country evidence. Journal of Financial Intermediation, 35, 1-16.

Demirgüç-Kunt, A., \& Huizinga, H. (2010). Bank activity and funding strategies: The impact on risk and returns. Journal of Financial Economics, 98, 626-650.

Detragiache, E., Tressel, T., \& Turk-Ariss, R. (2018). Where Have All the Profits Gone? European Bank Profitability Over the Financial Cycle. IMF working paper WP/18/99.
Dickey, D. A., \& Fuller, W. A. (1979). Distribution of the estimators for autoregressive time series with a unit root. Journal of the American Statistical Association, 47, 427-431.

Eggertsson, G. B., Juelsrud, R. E., Summers, L. H., \& Wold, E. G. (2019). Negative Nominal Interest Rates and the Bank Lending Channel. NBER working paper 25416.

Glosten, R. L., Jagannathan, R., \& Runkle, D. E. (1993). On the relation between the expected value and the volatility of the nominal excess return on stocks. The Journal of Finance, 48(5), 1779-1801.

Hacker, R. S., \& Hatemi-J, A. (2005). A test for multivariate ARCH effects. Applied Economics Letters, 12, 411-417.

Heider, F., Saidi, F., \& Schepens, G. (2019). Life below zero: Bank lending under negative policy rates, forthcoming in the Review of Financial Studies.

Köhler, M. (2015). Which banks are more risky? The impact of business models on bank stability. Journal of Financial Stability, 16, 195-212.

Kortela, T. (2016). A Shadow Rate Model with Time-Varying Lower Bound of Interest Rates Bank of Finland Research Discussion Paper no 19/2016.

Krippner, L. (2015). Zero lower bound term structure modeling (Palgrave Macmillan US).

Kusi, B. A., Agbloyor, E. K., Gyeke-Dako, A., \& Asongu, S. A. (2020). Financial Sector transparency and net interest margins: Should the private or public Sector lead financial Sector transparency? Research In International Business and Finance, 54, Article 101260.

Kwiatkowski, D., Phillips, P. C. B., Schmidt, P., \& Shin, Y. (1992). Testing the null hypothesis of stationarity against the alternative of a unit root. Journal of Econometrics, 54(1-3), 159-178.

Lemke, W., \& Vladu, A. (2014). A shadow-rate term structure model for the euro area. Discussion paper. European Central Bank.

Lopez, J. A., Rose, A. K., \& Spiegel, M. M. (2020). Why have negative nominal interest rates had such a small effect on bank performance? Cross-country evidence. European Economic Review, 124, Article 103402.

Pericoli, M., \& Taboga, M. (2015). Understanding policy rates at the zero lower bound: Insights from a Bayesian shadow rate model. Discussion paper 1023. Bank of Italy.

Roengpitya, R., Tarashev, N., \& Tsatsaronis, K. (2014). Bank business models. BIS Quarterly Review, (December 2014), 55-65.

Turk-Ariss, R. (2016). Negative Interest Rates: How Big a Challenge for Large Danish and Swedish Banks? IMF working paper WP/16/198.

Wu, C., \& Xia, F. (2016). Measuring the macroeconomic impact of monetary policy at the zero lower bound. Journal of Money, Credit, and Banking, 48, 253-291.

Xu, T. T., Hu, K., \& Das, U. S. (2019). Bank Profitability and Financial Stability. IMF working paper WP/19/5.

Zivot, E., Andrews, K., \& K.. (1992). Further evidence on the great crash, the oil price shock, and the unit-root hypothesis. Journal of Business and Economic Statistics, 10 (10), 251-270. 